\title{
Crystal structure of a human $\mathrm{GABA}_{\mathrm{A}}$ receptor
}

\author{
Paul S. Miller ${ }^{1}$ and A. Radu Aricescu ${ }^{1}$ \\ ${ }^{1}$ Division of Structural Biology, Wellcome Trust Centre for Human Genetics, University of Oxford, \\ Roosevelt Drive, Oxford OX3 7BN, United Kingdom.
}

\section{Summary}

Type-A $\gamma$-aminobutyric acid receptors $\left(\mathrm{GABA}_{\mathrm{A}} \mathrm{Rs}\right)$ are the principal mediators of rapid inhibitory synaptic transmission in the human brain. A decline in $\mathrm{GABA}_{\mathrm{A}} \mathrm{R}$ signalling triggers hyperactive neurological disorders such as insomnia, anxiety and epilepsy. Here we present the first threedimensional structure of a $\mathrm{GABA}_{\mathrm{A}} \mathrm{R}$, the human $\beta 3$ homopentamer, at $3 \AA$ resolution. This structure reveals architectural elements unique to eukaryotic Cys-loop receptors, explains the mechanistic consequences of multiple human disease mutations and shows a surprising structural role for a conserved $\mathrm{N}$-linked glycan. The receptor was crystallised bound to a previously unknown agonist, benzamidine, opening a new avenue for the rational design of $\mathrm{GABA}_{\mathrm{A}} \mathrm{R}$ modulators. The channel region forms a closed gate at the base of the pore, representative of a desensitised state. These results offer new insights into the signalling mechanisms of pentameric ligand-gated ion channels and enhance current understanding of GABAergic neurotransmission.

\section{Introduction}

In response to binding the neurotransmitter GABA, released at inhibitory synapses, $\mathrm{GABA}_{\mathrm{A}} \mathrm{R}$ chloride channels open and depress neuronal excitability in the adult central nervous system ${ }^{1}$. GABA ${ }_{A}$ Rs belong to a superfamily of pentameric ligand-gated ion channels (pLGICs) known as the Cys-loop receptors, that include the cation-selective nicotinic acetylcholine receptors (nAChRs) and serotonin type- 3 receptors $\left(5 \mathrm{HT}_{3} \mathrm{Rs}\right)$, as well as anion-selective glycine receptors (GlyRs) ${ }^{2}$. These molecules assemble as pentamers from a variety of subunits. In human $\mathrm{GABA}_{\mathrm{A}} \mathrm{Rs}$ these subunits are encoded by nineteen different genes: $\alpha 1-6, \beta 1-3, \gamma 1-3, \delta, \varepsilon, \theta, \pi$ and $\rho 1-3^{3}$. Most physiological heteromeric formats are thought to include two $\alpha$, two $\beta$ and one other, most frequently a $\gamma$ subunit ${ }^{4}$. $\beta 3$ subunits also efficiently assemble into functional homomeric channels, and although they have yet to be identified as discrete populations in the brain, they serve as meaningful models for the heteromeric receptors ${ }^{5}$. Each subunit contributes an extracellular domain of

Users may view, print, copy, and download text and data-mine the content in such documents, for the purposes of academic research, subject always to the full Conditions of use:http://www.nature.com/authors/editorial_policies/license.html\#terms

Correspondence and requests for materials should be addressed to A.R.A. (radu@ strubi.ox.ac.uk) or P.S.M. (paul@strubi.ox.ac.uk). Author Contributions: The authors have jointly contributed to the project design, data analysis and manuscript preparation. Experimental work was performed by P.S.M. (protein expression, purification, crystallization, ligand binding assays and electrophysiology) and A.R.A. (crystallography).

Author Information: The coordinates and the structure factors have been deposited in the Protein Data Bank under the accession code 4COF. Reprints and permissions information is available at www.nature.com/reprints. A patent application related to the use of benzamidine derivatives as $\mathrm{GABA}_{\mathrm{A}}$ receptor modulators has been filed by the University of Oxford. Readers are welcome to comment on the online version of the paper. 
200-250 amino acids, an a-helical M1-M4 transmembrane bundle and an M3-M4 intracellular loop of 85-255 residues $^{6}$. Neurotransmitter molecules bind at extracellular pockets between subunits to induce a conformational switch that crosses to the transmembrane region to open the ion channel ${ }^{7}$. GABA $\mathrm{A}_{\mathrm{R}} \mathrm{R}$ are the targets of a wide range of drugs including benzodiazepines ${ }^{8}$, used in treatment of epilepsy, insomnia, anxiety and panic disorder, and the intravenous general anaesthetics propofol and etomidate ${ }^{5,9}$.

$\mathrm{GABA}_{\mathrm{A}}$ Rs also mediate alcohol inebriation ${ }^{10}$ and are targets for endogenous modulators such as neurosteroids ${ }^{11}$.

In the absence of $\mathrm{GABA}_{\mathrm{A}} \mathrm{Rs}$ structural information, insights relied on analogies with related proteins. The soluble acetylcholine binding protein (AChBP) provided the first highresolution model for the extracellular region ${ }^{12}$. Ground-breaking electron microscopic studies gradually led to an atomic model (at $4 \AA$ ) of a complete heteromeric nAChR from the Torpedo marmorata electric organ ${ }^{13,14}$, and a general framework for molecular understanding of pLGICs. Subsequently, crystal structures of two bacterial homologues, ELIC $^{15}$ and GLIC $^{16}$, as well as the first structure of an anion-selective Cys-loop receptor, the Caenorhabditis elegans glutamate-gated chloride channel a homopentamer (GluCla $)^{17}$, were reported, providing insights into potential mechanisms of interaction with orthosteric ligands and allosteric modulators ${ }^{17,18}$. Nevertheless, due to limited sequence identities, these models alone cannot adequately explain $\mathrm{GABA}_{\mathrm{A}} \mathrm{R}$ receptor assembly, ligand binding and modulation, its gating mechanism, or the consequences of numerous human mutations linked to epilepsy and insomnia. Aiming to address these unknowns, here we report the crystal structure of a human $\mathrm{GABA}_{\mathrm{A}} \mathrm{R}$, the $\beta 3$ homopentamer.

\section{Architecture of the $G A B A_{A} R \beta 3$ homopentamer}

Crystallisation of human $\mathrm{GABA}_{\mathrm{A}} \mathrm{R} \beta 3$ required truncation of the intracellular loop between transmembrane helices 3 and 4 (M3-M4). Residues from Gly308 to Asn421 were substituted by a linker sequence, SQPARAA ${ }^{19}$, to give the construct $\mathrm{GABA}_{\mathrm{A}} \mathrm{R}-\beta 3_{\text {cryst }}$ (residue numbering used here corresponds to the mature isoform 1, i.e. Gln26 in UniProt entry $\mathrm{P} 28472$ is $\mathrm{G} \ln 1$ in $\left.\mathrm{GABA}_{\mathrm{A}} \mathrm{R}-\beta 3_{\text {cryst }}\right)$. GABA $\mathrm{A}-\beta 3_{\text {cryst }}$ solubilised in detergent retained the ability to bind agonists (GABA and histamine), channel blockers (fipronil and picrotoxin) and the anaesthetic etomidate (Extended Data Fig. 1a-e). Furthermore, in patch-clamped HEK293T cells expressing $\mathrm{GABA}_{\mathrm{A}} \mathrm{R}-\beta 3_{\text {cryst }}$, application of the $\mathrm{GABA}_{\mathrm{A}} \mathrm{R} \beta 3$ agonists histamine or propofol induced inward currents that were inhibited by the channel blockers fipronil and picrotoxin (Extended Data Fig. 1f, g).

We crystallized and determined the structure of $\mathrm{GABA}_{\mathrm{A}} \mathrm{R}-\beta 3_{\text {cryst }}$ at $3 \AA$ resolution (Extended Data Table 1). Viewed perpendicular to the central five-fold pseudo-symmetry axis, the receptor approximates a cylinder $110 \AA$ in height, with diameter ranging 60 to $80 \AA$ (Fig. 1a), spanning the plasma membrane and protruding $\sim 65 \AA$ into the extracellular space. Viewed along the same pseudo-symmetry axis from the extracellular side, the pentamer has a toroidal (doughnut-like) profile, surrounded by fifteen (three per subunit) N-linked glycans (Fig. 1b). Each extracellular domain (ECD) comprises an N-terminal a-helix (a1) followed by ten $\beta$-strands folded into a curled $\beta$-sandwich, topologically similar to other family members characterised to date (Fig. 1c, Extended Data Figs. 2 and 3). A second a-helix 
(a2), between $\beta$-strands 3 and 4 , is located under the $a 1$ helix (Fig. 1c). Four additional helices (M1-M4) from each subunit come together to create the pentameric transmembrane domain (TMD), with M2 segments lining a pore that tapers as it traverses towards the intracellular side of the membrane (Fig. 1b-d).

On the extracellular side, water and solutes access the pore from a vestibule surrounded by the ECDs and from lateral tunnels situated between the ECDs that are lined by an excess of negatively charged groups, suggesting putative cation modulation sites (Fig. 1c, e and Extended Data Fig. 4a, d, g, h).

A positively-charged ring halfway down the vestibule hosts putative anion binding sites at each inter-subunit interface (Extended Data Fig. $4 d$ ), revealed by peaks (visible to an $\sim 6 \sigma$ level) in $F_{o}-F_{c}$ electron density maps calculated following refinement without anions modelled (Extended Data Fig. 5a). Attempts to confirm the nature of these peaks by soaking heavy atom anions (e.g. iodide) into the crystals and analysis of anomalous electron density maps were inconclusive. However, placement of chloride ions followed by refinement satisfactorily accounts for these electron density features (Extended Data Fig. 5a-c). This positively-charged ring overlaps with a vestibule ion selectivity filter previously proposed for Cys-loop receptors ${ }^{20}$. Furthermore, these putative chloride sites are in spatial proximity (but structurally non-equivalent) to the "anion site 1" reported in the bacterial channel GLIC $^{21}$, and thus chloride ions might be important stabilizers of pLGIC assembly.

At the TMD level, two large non-overlapping pockets are located near residues previously inferred to bind the intravenous anaesthetics etomidate and propofol ${ }^{5,9}$ (Extended Data Fig. 6a-c). The putative propofol binding pocket is structurally distinct from the one identified in the bacterial channel GLIC ${ }^{18}$. The binding and transduction modes of propofol on $\mathrm{GABA}_{\mathrm{A}} \mathrm{R}-\beta 3_{\text {cryst }}$ and GLIC are therefore unrelated, as are its relative potencies. Propofol potentiates and activates $\mathrm{GABA}_{\mathrm{A}}$ Rs but inhibits $\mathrm{GLIC}^{5,18}$.

\section{Determinants of assembly}

The nineteen different $\mathrm{GABA}_{\mathrm{A}} \mathrm{R}$ subunits obey stringent rules for assembly specificity ${ }^{4}$, the molecular determinants of which are poorly understood. Comparing inter-subunit interfaces from pLGIC structures available to date reveals striking differences in the geometry and thermodynamics of complex formation, with $\mathrm{GABA}_{\mathrm{A}} \mathrm{R}-\beta 3_{\text {cryst }}$ subunits forming the most extensive, energetically favourable interactions. These occur in particular between ECDs through patchworks of hydrogen bonds, salt bridges and van der Waals contacts (Fig. 2 a-c and Extended Data Fig. 7a-e). Within the upper portions of the ECDs, between the a 1 helices of adjacent subunits, the side chains of Arg26 and Asp17 form a salt-bridge network extending to Asp24 and Lys13 (Fig. 2b), an interaction specific to $\beta-\beta$ and $a-\beta$ subunits in human $\mathrm{GABA}_{\mathrm{A}}$ Rs (Extended Data Fig. 3). Between the $\mathrm{a} 2$ helices, the inter-subunit interface is stabilised by a network of hydrogen bonds and salt bridges surrounding $\operatorname{Arg} 86$, specific to the GABA ${ }_{A} R-\beta$ and GlyR subunits (Fig. $2 b$ and Extended Data Fig. 3). The loop connecting the $\alpha 1$ helix with the $\beta 1$ strand also bridges this interface and mutations in it (or its proximity) are associated with childhood absence epilepsy and febrile seizures ${ }^{22,23}$ (Extended Data Fig. 3). A GABA ${ }_{A} R-\beta 3$ Gly7Arg mutation that excludes $\gamma 2$ subunits from 
heteromeric $\mathrm{GABA}_{\mathrm{A}} \mathrm{Rs}^{22}$ opposes and is likely to perturb the a1- $\beta 1$ loop conformation (Fig. $2 b)$. $A$ GABA $A$ R- $\gamma 2$ Arg 43 Gln mutation (equivalent to $A r g 28 G \ln$ in $G_{A B A} R-\beta 3_{\text {cryst }}$ ) that excludes $\gamma 2$ subunits ${ }^{23}$ resides within the loop and is predicted to disrupt the backbone organisation of the $a 1-\beta 1$ loop (Fig. $2 b$ ).

Inter-subunit contacts between the central portions of ECDs involve the $\beta 4, \beta 5, \beta 5^{\prime}$ and $\beta 6$ strands and flanking loops. The $\beta 5-\beta 5^{\prime}$ loop is extended in $\mathrm{GABA}_{\mathrm{A}} \mathrm{R}-\beta 3_{\text {cryst }}$ and GluCla compared to nAChRs and AChBP (Extended Data Fig. 2d), and protrudes into the neighbouring subunit (Fig. 2c). The $\beta 5-\beta 5^{\prime}$ loop His 107 , strictly conserved in $\mathrm{GABA}_{\mathrm{A}}$ and Gly receptors, and main chain amino groups in positions 104 and 108 coordinate putative chloride anions across this boundary (within the positively-charged ring lining the vestibule discussed earlier; Fig. 2c and Extended Data Fig. 5c). Further interface contacts include a salt bridge network centred on Asp101 and Arg129, and a potential cation- $\pi$ interaction between Lys103 and Phe105, both likely to influence assembly specificity based on residue conservation patterns (Fig. 2c and Extended Data Fig. 3). Mutations within this ECD interface are linked to epileptic encephalopathies, for example Asn85 Asp ${ }^{24}$ which will remodel interactions with basic residues adjoining the $\beta 5-\beta 5^{\prime}$ loop (Fig. $2 \mathrm{c}$ ).

\section{Neurotransmitter pocket and binding mode of a novel agonist}

The neurotransmitter-binding pocket of $\mathrm{GABA}_{\mathrm{A}} \mathrm{Rs}$ is located between ECDs. It comprises the $\beta 4$ strand and adjacent residues (Asp95-Leu99), part of the $\beta 7-\beta 8$ loop (Glu155-Tyr159) and the $\beta 9-\beta 10$ loop (Phe200-Tyr 205) from the "principal" ("P") face, also known as loops A-C, respectively. The "complementary" ("C") face in $\mathrm{GABA}_{\mathrm{A}} \mathrm{R}-\beta 3_{\text {cryst }}$ comprises a segment of the $\beta 2$ strand (Tyr62-Gln64) and the $\beta 6$ strand (Leu125-Arg129), also known as loops $\mathrm{D}$ and $\mathrm{E}$ respectively, which come from equivalent motifs in a subunits in heteromers (Fig. 3a-c and Extended Data Fig. 3) ${ }^{25}$.

The $\beta 9-\beta 10$ loop adopts a "closed" conformation over the site, consistent with an agonistbound conformation ${ }^{17,26-28}$ (Extended Data Fig. 8). Closure is stabilised by salt-bridges between the side chains of Arg207, Glu153 and Glu155 (Fig. 3b,c), residues previously implicated in GABA binding and activation ${ }^{29-31}$, and for which analogous interactions are implicated in binding and activation in $\mathrm{nAChRs}{ }^{12,32}$.

We observed large positive peaks in the $F_{o^{-}} F_{c}$ electron density map in all five neurotransmitter-binding sites, that are accounted for by benzamidine molecules, an additive that helped us obtain high-resolution diffracting crystals (Extended Data Fig. 5d-f). To our knowledge, benzamidine or its derivatives have not previously been reported to act as $\mathrm{GABA}_{\mathrm{A}} \mathrm{R}$ ligands. We recorded $\mathrm{GABA}_{\mathrm{A}} \mathrm{R}-\beta 3_{\text {cryst }}$ currents in $\mathrm{HEK} 293 \mathrm{~S}-\mathrm{GnTI}^{-}$cells, and found benzamidine to behave as an agonist capable of inducing desensitisation $\left(\mathrm{EC}_{50}=61 \pm\right.$ $12 \mu \mathrm{M} ; \mathrm{n}=4$; Fig. 3d, e). Thermostabilisation of $\mathrm{GABA}_{\mathrm{A}} \mathrm{R}-\beta 3_{\text {cryst }}$ in detergent micelles by benzamidine revealed a similar sensitivity to histamine (benzamidine $\mathrm{EC}_{50}=370 \pm 180 \mu \mathrm{M}$; histamine $\mathrm{EC}_{50}=400 \pm 150 \mu \mathrm{M} ; \mathrm{n}=3$; Fig. 3d and Extended Data Fig. 1c). Classically, benzamidine is known as a highly potent serine-protease inhibitor, derivatives of which are in clinical trials for prevention of blood clotting ${ }^{33}$. However, given that $\mathrm{GABA}_{\mathrm{A}} \mathrm{R}-\beta 3$ agonists such as histamine act instead as potentiators of heteromeric $\mathrm{GABA}_{\mathrm{A}} \mathrm{Rs}$, 
characterization of benzamidine derivatives as positive modulators may offer new opportunities in drug development.

The benzamidine benzyl ring stacks between side chains Phe200 and Tyr62, while its amidinium group hydrogen bonds with the Glu155 side-chain and backbone carbonyls of Ser156 and Tyr157, and participates in putative cation- $\pi$ interactions with the Tyr157 and Tyr205 aromatic rings (Fig. 3b,c). This binding mode is reminiscent of the "principal" face one observed in GluCla and AChBP (Extended Data Fig. 8a, b). Two epileptic encephalopathies are linked to mutations in this region, $\beta 3$ subunit Asp95Asn and Glu155Gly ${ }^{24}$. Loss of Asp95, which hydrogen bonds Ser156 and Tyr157, will likely destabilise the conformation of the $\beta 7-\beta 8$ loop, while Glu155Gly will impair binding of amino-group containing ligands (Fig. 3b,c and Supplementary Discussion).

\section{The impact of $\mathrm{N}$-linked glycosylation}

Two of the three N-linked glycosylation sites present in each subunit (Asn8, only visible in chain A, and Asn80) are occupied by residual GlcNAc moieties following endoglycosidase F1 treatment. The third site, Asn 149 on the $\beta 7$ strand (Fig. 4), is conserved in almost all $\mathrm{GABA}_{\mathrm{A}} \mathrm{R}-\beta, \mathrm{nAChR}$ and $5 \mathrm{HT}_{3} \mathrm{R}$ subunits (Extended Data Fig. 3) and was resistant to enzymatic digestion (Extended Data Fig. 5g-i). This glycan extends along the $\beta 9$ and $\beta 10$ strands that support the agonist binding "loop C", providing further contacts between these units and the $\beta 7$ strand, which may facilitate the ECD-TMD signal transduction. Substitution of Asn149 in $\mathrm{GABA}_{\mathrm{A}} \mathrm{R}-\beta 2$ reduces sensitivity to $\mathrm{GABA}^{34}$, and in GlyRs, $\mathrm{Zn}^{2+}$ coordination between the same three $\beta$-strands potentiates agonist sensitivity ${ }^{35}$. Furthermore, mutation of Arg 192 at the core of this network of glycan interactions is associated with chronic insomnia and increases the inactivation rate of $\mathrm{GABA}_{\mathrm{A}} \mathrm{Rs}^{36}$. Finally, the equivalent glycan in $\mathrm{nAChR}$ a 1 also contacts the outer face of the ECD, and its enzymatic cleavage decreases nAChR function ${ }^{37}$.

\section{Structural coupling between the extracellular and transmembrane domains}

For a neurotransmitter binding event to transmit to the channel gate, a signal must be transduced across the ECD-TMD interface. The inner and outer $\beta$-sheets of each $\mathrm{GABA}_{\mathrm{A}} \mathrm{R}$ $\beta 3_{\text {cryst }}$ ECD come together at the base through a conserved salt-bridge between $\beta 1-\beta 2$ loop Glu52 and $\beta 10$-strand Arg216 14,38 (Extended Data Fig. 7e). Beneath this, in each subunit the ECD-TMD interface consists of two clusters of interactions: an array of polar contacts linking the outer portion of the M2-M3 loop with the $\beta 6-\beta 7$ ("Cys") loop (Fig. 5a); and van der Waals contacts between residues in the inner portion of the M2-M3 loop near the pore, the $\beta 1-\beta 2$ loop and the $\beta 6-\beta 7$ loop (Fig. $5 b$ ). Central to both clusters is Pro144 in the $\beta 6-\beta 7$ loop, conserved in all pLGICs (Extended Data Fig. 3) and adopting a cis conformation, which orients the neighbouring Tyr143 backbone carbonyl downwards to hydrogen bond with M3 helix backbone amino groups (Fig. 5a). These contacts ensure that the $\mathrm{GABA}_{\mathrm{A}} \mathrm{R}$ $\beta 3_{\text {cryst }}$ ECD-TMD interface is tightly structurally coupled, with a solvent inaccessible surface area of $689 \AA^{2}, 100 \AA^{2}$ larger than observed in ELIC, but comparable to those observed in GluCla, GLIC, and the three nAChR structures solved in a membrane context by electron microscopy (Extended Data Fig. 9a). Nevertheless, despite similarly strong 
interfaces, structural alignments of $\mathrm{GABA}_{\mathrm{A}} \mathrm{R}-\beta 3_{\text {cryst }}$ with other pLGICs reveal differences in their ECD-TMD relative orientations, where rotations within a $\sim 20^{\circ}$ range likely reflect the multiplicity of states (resting, activated and desensitised) that these receptors occupy 39 (Extended Data Fig. 9b-f).

Mutations linked to epileptic encephalopathies highlight the importance of the ECD-TMD region $^{24,40}$. One such mutation, $\mathrm{GABA}_{\mathrm{A}} \mathrm{R}-\beta 3$ Tyr277Cys will reduce hydrogen bond connectivity between the M2-M3 loop and the $\beta 6-\beta 7$ loop and disrupt a stacking interaction with the Arg141 guanidinium group (Fig. 5a). Another mutation, GABA ${ }_{A} R-\beta 1$ Phe246Ser ( $\beta 3$ Phe 221) is located at the top of M1 and will disrupt hydrophobic association with the critical Tyr143/Pro144 motif at the apex of the $\beta 6-\beta 7$ loop (Fig. 5b). A Lys289Met mutation reported in $\mathrm{GABA}_{A} \mathrm{R}-\gamma 2$ (Lys 274 in $\mathrm{GABA}_{\mathrm{A}} \mathrm{R}-\beta 3_{\text {cryst }}$ ) affects a residue whose side chain, very well ordered in electron density maps, reaches across a neighbouring subunit (Fig. 5b and Extended Data Fig. 7e). This residue is conserved in GlyRs, for which mutations are linked to the rare genetic startle disorder hyperekplexia, and where detailed kinetic analysis of GlyR a 1 Lys276Glu has revealed a significantly slower gating ${ }^{41}$. Thus, based on the $\mathrm{GABA}_{\mathrm{A}} \mathrm{R}-\beta 3_{\text {cryst }}$ structure, it appears that this lysine facilitates the coordination of intersubunit motions.

\section{Channel structure and the desensitisation mechanism}

The $\mathrm{GABA}_{\mathrm{A}} \mathrm{R}-\beta 3_{\text {cryst }}$ pore is lined by five $\mathrm{M} 2$ helices (Fig. 1a-d), supporting "rings" of residues between positions $-5^{\prime}$ and $20^{\prime}$ (Fig. 6a). In GABA $A_{A}$ R- $\beta 3_{\text {cryst }}$ the M2 helices taper inwards from the $13^{\prime} \mathrm{Thr} 263$ down to the intracellular border where the $-2^{\prime}$ Ala248 side chains define the narrowest point, just $3.15 \AA$ in diameter (Fig. 6a,b). This pore is too narrow to permit the passage of chloride anions (with a Pauling radius of $1.8 \AA$ ) and therefore delineates a closed gate. However, this geometry fundamentally differs from closed structures reported to date, ELIC ${ }^{15}$ and Torpedo $\mathrm{nAChR}^{14}$, which exhibit almost vertical M2 helices and have closed gates in the extracellular portion of the pore ( $9^{\prime}$ up to $20^{\prime}$ ) formed by bulky hydrophobic side chains (Fig. $6 \mathrm{~b}$ ). In $\mathrm{GABA}_{\mathrm{A}} \mathrm{R}-\beta 3_{\text {cryst }}$ none of the M2 hydrophobic rings ( $1^{\prime}$ Val, $3^{\prime}$ Leu, $5^{\prime}$ Ile, $8^{\prime}$ Val, $9^{\prime}$ Leu, $11^{\prime}$ Met, $14^{\prime}$ Ile and $18^{\prime}$ Leu) line the pore. Instead, its pore trajectory more closely resembles the open conformations of GLIC ${ }^{16}$ and $\mathrm{GluCla}^{17}$, that are narrowest at the intracellular border (Fig. $6 \mathrm{~b}$ and Extended Data Fig. $9 \mathrm{~g})$.

The pore-lining residues in $\mathrm{GABA}_{\mathrm{A}} \mathrm{R}-\beta 3_{\text {cryst }}$ (Fig. 6a) overlap with the equivalent $\alpha$-subunit residues in the $\mathrm{GABA}_{\mathrm{A}} \mathrm{R}$ identified by cysteine accessibility studies and with the open $\mathrm{nAChR}$ pore residues identified by protonation of introduced charged residues ${ }^{42,43}$. However, the $9^{\prime}$ Leu residues in $\mathrm{GABA}_{\mathrm{A}} \mathrm{R}-\beta 3_{\text {cryst }}$ (conserved across the mammalian Cysloop receptors) are rotated out of the pore, with side chains placed between neighbouring $\mathrm{M} 2$ helices. This rotation is not observed in the open-to-closed M2 flexion motion in $\mathrm{nAChR}{ }^{44}$. Irrespectively, rotation of $\mathrm{M} 2$ cannot account for the closed state of $\mathrm{GABA}_{\mathrm{A}} \mathrm{R}$ $\beta 3_{\text {cryst }}$ because superposition of each TMD individually onto open pore GluCla TMDs to remove its influence reveals that the $\mathrm{GABA}_{\mathrm{A}} \mathrm{R}-\beta 3_{\text {cryst }}$ pore would remain closed (Fig. 6c-f). Thus, the closed pore of $\mathrm{GABA}_{\mathrm{A}} \mathrm{R}-\beta 3_{\text {cryst }}$ is accounted for by a unique conformation of its M2 helix (Fig. 6a and Extended Data Fig. 9g). 
The expanded extracellular portion of the pore in $\mathrm{GABA}_{\mathrm{A}} \mathrm{R}-\beta 3_{\text {cryst }}$ is stabilised by two rings of salt-bridges. The first one involves $17^{\prime}$ His 267 and $20^{\prime}$ Glu270 from adjacent M2 helices (Extended Data Fig. 7e). His267 lines both the pore and an inter-subunit cavity, coordinating $\mathrm{Zn}^{2+}$ for inhibition or propofol for potentiation ${ }^{5,45}$ (Extended Data Fig. 6b,c and 7e). The second ring is an intra-subunit interaction between the side chains of 19' Arg269 and M3 Asp282, which retracts M2 against M3 (Extended Data Fig. 7e). This ring is conserved in $\mathrm{GABA}_{\mathrm{A}} \mathrm{R}$ a-subunits and GlyR a-subunits, and substitutions of GlyR a1 19' Arg are the most frequent cause of the human genetic startle disorder, hyperekplexia, with disease mutations $19^{\prime}$ Leu and $19^{\prime}$ Gln decoupling agonist binding from gating ${ }^{46}$.

The contracted intracellular portion of the pore is confined by the conformation of Tyr299 side chains, which press downwards upon the back of the M2 gate, compressing it shut (Fig. $6 \mathrm{~g}$ ). Aromatic Phe or Tyr residues occupy this position across all human $\mathrm{GABA}_{\mathrm{A}} \mathrm{R}$ and GlyR subtypes and in C. elegans GluCla. Strikingly however, in the GluCla open pore the equivalent Phe294 side chain points upwards, preventing such compression (Fig. 6g). During the gating process, conformation switching of side chains at this key position might account for local desensitisation, and drugs that potentiate function by blocking desensitisation ${ }^{47-49}$ might do so by disabling this aromatic switch. A desensitised state of $\mathrm{GABA}_{\mathrm{A}} \mathrm{R}-\beta 3_{\text {cryst }}$ is in agreement with our electrophysiological recordings of benzamidineinduced desensitising currents measured in HEK cells at saturating concentrations (10 mM), which approach those used in crystallisation (33 mM; Fig. 3e). Furthermore, in heteromeric $\mathrm{GABA}_{\mathrm{A}} \mathrm{Rs}$, swapping the $\beta$-subunit intracellular border with the equivalent $\mathrm{nAChR}$ residues ablates desensitisation $^{50}$.

\section{Conclusion}

Here we present the first $X$-ray structure of a $\mathrm{GABA}_{\mathrm{A}} \mathrm{R}$, the human $\beta 3$ homopentamer, cocrystallised with a novel agonist, benzamidine. $\mathrm{GABA}_{\mathrm{A}} \mathrm{R}-\beta 3_{\text {cryst }}$ has a closed $\beta 9-\beta 10$ loop, being in an agonist-bound state, but the pore is shut, consistent with a desensitised conformation. To our knowledge, this is the first time when a pLGIC desensitised state has been described crystallographically. These results shed new light on the conformational transitions that occur across pLGICs and provide a rational basis for understanding how human disease mutations that cause epilepsy, insomnia and hyperekplexia impact upon $\mathrm{GABA}_{\mathrm{A}} \mathrm{R}$ assembly, glycosylation, agonist binding, as well as the signal transduction and gating processes.

\section{Methods}

\section{Construct design, optimization and small-scale screening}

A synthetic cDNA construct encoding the full length human $\mathrm{GABA}_{\mathrm{A}} \mathrm{R} \beta 3$ subunit, based on GenBank accession number M82919, was codon-optimised for expression in mammalian cells. Approximately one-hundred construct variants were subsequently generated by PCR, to evaluate the consequences of $\mathrm{N}$-linked glycosylation sites removal, mutation of Cysteine residues, $\mathrm{N}$-terminal and $\mathrm{C}$-terminal truncations, truncations in the intracellular loop connecting the transmembrane helices 3 and 4 (M3-M4) and introduction of chimeric domains (such as T4 lysozyme) into predicted flexible loops. These constructs were cloned 
into the pHLsec vector ${ }^{51}$, making use of the secretion signal sequence provided by the plasmid. To facilitate small scale screening of protein expression, solubilisation, purification and stabilization conditions, constructs were tagged $\mathrm{N}$-terminally with monoVenus ${ }^{52,53}$ and C-terminally with a nine amino acid sequence derived from bovine rhodopsin (TETSQVAPA) that is recognised by the Rho-1D4 monoclonal antibody (University of British Columbia) ${ }^{54,55}$. Small-scale expression trials were performed by transient transfection in adherent HEK293T cell cultures, as previously described ${ }^{51}$. Expression levels of recombinant $\mathrm{GABA}_{\mathrm{A}} \mathrm{R}-\beta 3$ variants were evaluated by western blotting using Rho-1D4 as a primary antibody and the efficiency of their cell surface trafficking was monitored by wide-field fluorescence microscopy.

Suitable constructs underwent high-throughput solubilisation screening by $\mathrm{FSEC}^{56}$, using a broad panel of detergents. For this and all subsequent steps, small-scale expression was performed in HEK293S-GnTI ${ }^{-}$cells, to reduce $N$-linked glycosylation heterogeneity ${ }^{57,58}$. Cells were transiently transfected using lipofectamine (Invitrogen) in an adherent format and 48-72 $\mathrm{h}$ later were re-suspended and solubilized in a $10 \mathrm{mM}$ HEPES pH 7.2, $300 \mathrm{mM} \mathrm{NaCl}$ buffer supplemented with a $1: 100(\mathrm{v} / \mathrm{v})$ dilution of mammalian protease inhibitor solution (Sigma-Aldrich) and $1 \%$ detergent, for $2 \mathrm{~h}$ at $4{ }^{\circ} \mathrm{C}$. Insoluble material was removed by centrifugation $(10,000 \mathrm{~g}, 15 \mathrm{~min})$ and the supernatant incubated for $2 \mathrm{~h}$ at $4{ }^{\circ} \mathrm{C}$ with purified Rho-1D4 antibody coupled to CNBr-activated sepharose beads (GE Healthcare). Resinbound samples were washed with $10 \mathrm{mM}$ HEPES pH 7.2, $300 \mathrm{mM} \mathrm{NaCl}$ buffer containing detergent at $3 \times \mathrm{CMC}$ and receptor constructs were eluted overnight in the same buffer supplemented with $500 \mu \mathrm{M}$ TETSQVAPA peptide (Genscript). For size-exclusion chromatography (SEC), samples were loaded onto a Superdex 200 3.2/300 column (GE Healthcare) equilibrated in $10 \mathrm{mM}$ HEPES pH 7.2, $300 \mathrm{mM} \mathrm{NaCl}, 0.02 \%$ n-Dodecyl- $\beta$-Dmaltopyranoside (DDM, Anatrace), attached to a high-performance liquid chromatography system with automated micro-volume loader and in-line fluorescence detection (Shimadzu).

\section{Large-scale protein expression and purification}

In preliminary large-scale expression trials, six-litre batches of HEK293S-GnTI ${ }^{-}$cells were grown in suspension to densities of $2 \times 10^{6}$ cells ml$^{-1}$ in Protein Expression Media (PEM, Invitrogen) supplemented with L-glutamine, non-essential amino-acids (Gibco) and 1\% foetal calf serum (Sigma). For transient transfection, cells from 1 litre cultures were collected by centrifugation ( $200 \mathrm{~g}$ for $5 \mathrm{mins}$ ) and resuspended in $150 \mathrm{ml}$ Freestyle medium (Invitrogen) containing $3 \mathrm{mg}$ PEI Max (Polysciences) and $1 \mathrm{mg}$ plasmid DNA, followed by a 3-6 h shaker-incubation. Subsequently, culture media were topped up to 1 litre with PEM containing $4 \mathrm{mM}$ valproic acid. Typically, 40-70\% transfection efficiencies were achieved, as assessed by control transfections with a monoVenus-expressing plasmid ${ }^{52,53} \cdot 48-72 \mathrm{~h}$ post-transfection cell pellets were collected, snap-frozen in liquid $\mathrm{N} 2$ and stored at $-80{ }^{\circ} \mathrm{C}$.

FSEC screening indicated that decyl maltose neopentyl glycol (DMNG, Anatrace) is the most suitable detergent for handling $\mathrm{GABA}_{\mathrm{A}} \mathrm{R}-\beta 3$ constructs, and that protein stability is enhanced by the addition of cholesterol hemisuccinate (CHS, Anatrace). Therefore, the solubilisation buffer contained $10 \mathrm{mM}$ HEPES $\mathrm{pH} 7.2,300 \mathrm{mM} \mathrm{NaCl}, 1 \%$ DMNG and $0.05 \%$ CHS. Proteins were affinity-purified on Rho-1D4 antibody-coupled beads as 
described above, concentrated by ultrafiltration to $1-2 \mathrm{mg} / \mathrm{ml}$ using $100-\mathrm{kDa}$ cut-off membranes (Millipore) and applied to a Superdex 200 10/300 gel filtration column (GE Healthcare) equilibrated in $10 \mathrm{mM}$ HEPES pH 7.2, $150 \mathrm{mM} \mathrm{NaCl}, 0.007 \%$ (w/v) DMNG, $0.0006 \%$ (w/v) CHS.

\section{The GABA $A-\beta 3_{\text {cryst }}$ construct}

Residue numbers correspond to the Uniprot entry P28472. Throughout the manuscript, in agreement with the established customs within the ion channel community and to facilitate comparisons between our results and others', we adopted a numbering scheme whereby Gln26 becomes Gln1, as the first residue of the mature protein (after cleavage of the secretion signal sequence).

The most suitable construct in terms of yield and monodispersity spanned the full length of the mature $\mathrm{GABA}_{\mathrm{A}} \mathrm{R} \beta 3$ isoform 1 (from Gln26 to Asn473) but with the intracellular M3M4 loop (Gly333-Asn446) replaced with the short amino acid sequence SQPARAA ${ }^{59,60}$. This is the construct we refer to as $\mathrm{GABA}_{\mathrm{A}} \mathrm{R}-\beta 3_{\text {cryst }}$, because it eventually led to the crystal structure described in this manuscript. The $\mathrm{N}$-terminal region is native (the $\mathrm{N}$-terminal monoVenus tags was not present on the construct used for large scale expression), however we maintained the C-terminal TETSQVAPA tag for affinity-purification.

Aiming to obtain the highest possible protein yields, a HEK293S-GnTI- cell line stably expressing $\mathrm{GABA}_{\mathrm{A}} \mathrm{R}-\beta 3_{\text {cryst }}$ was generated as described previously ${ }^{61}$. Pure protein yields from this cell line were typically $\sim 0.02 \mathrm{mg} / \mathrm{g}$ cells (typically $10 \mathrm{~g}$ cells was obtained from 1 litre cell-media), roughly twice that of transient transfection.

\section{Crystallization and data collection}

The homopentameric $\mathrm{GABA}_{\mathrm{A}} \mathrm{R}-\beta 3_{\text {cryst }}$ contains $15 \mathrm{~N}$-linked glycosylation sites, bringing a considerable extra volume, flexibility and potential heterogeneity. Therefore, prior to crystallization, purified $\mathrm{GABA}_{\mathrm{A}} \mathrm{R}-\beta 3_{\text {cryst }}$ samples were concentrated to $3 \mathrm{mg} / \mathrm{ml}$ and incubated with $0.01 \mathrm{mg} / \mathrm{ml}$ endoglycosidase $\mathrm{F}^{62}$ for $2 \mathrm{~h}$ at room temperature. Sitting drop vapour diffusion crystallization trials were performed in 96-well Greiner Crystal Quick X plates, using 200nl protein plus 100nl reservoir dispensed by a Cartesian Technologies robot ${ }^{63}$. Plates were maintained at $6.5^{\circ} \mathrm{C}$ in a Formulatrix storage and imaging system. Initial crystals grew within 1-7 days in a range of conditions, however they were poorly diffracting (no better than $\sim 13 \AA$ ). Subsequent rounds of optimization by additive screening ${ }^{64}$ led to well diffracting crystals $(\sim 3 \AA)$, grown in $11.5 \%$ PEG 4000, $100 \mathrm{mM}$ $\mathrm{NaCl}, 100 \mathrm{mM} \mathrm{Li}_{2} \mathrm{SO}_{4}, 100 \mathrm{mM} \mathrm{N}$-(2-Acetamido)iminodiacetic acid pH 6.5, $2 \%$ (w/v) benzamidine. Crystals were cryoprotected by soaking in reservoir solution supplemented with $20 \%$ glycerol, followed by flash-freezing in liquid nitrogen. Diffraction images of $0.2^{\circ}$ oscillation were collected at the Diamond Light Source beamline I03, on a Pilatus 6M-F detector, and indexed, integrated and scaled using xia ${ }^{65}$. Data collection statistics are shown in Supplementary Table 1. 


\section{Structure determination, refinement and analysis}

The $\mathrm{GABA}_{\mathrm{A}} \mathrm{R}-\beta 3_{\text {cryst }}$ structure was solved by molecular replacement using the $C$. elegans glutamate-gated chloride channel a (GluCla ${ }^{66}$, PDB accession code 3RHW) as a search model in Phaser ${ }^{67}$. An initial round of automated model building, structure refinement and density modification was performed using Phenix AutoBuild ${ }^{68}$ followed by iterative steps of manual model building in $\operatorname{Coot}^{69}$ and refinement in Buster ${ }^{70}$. During the refinement/ building process it became clear that the $\mathrm{N}$-terminal region of one $\mathrm{GABA}_{\mathrm{A}} \mathrm{R}-\beta 3_{\text {cryst }}$ monomer (chain A) adopted a distinct, well-ordered, conformation because of its involvement in crystal contacts. As a result, the strict five-fold non-crystallographic symmetry (NCS) restraints strategy was replaced at later stages by a local structural similarity restraints NCS approach, to allow pruning of genuine differences among matching chains from the NCS relation ${ }^{71}$. The final model contains one $\mathrm{GABA}_{\mathrm{A}} \mathrm{R}-\beta 3_{\text {cryst }}$ homopentamer per asymmetric unit. The complete polypeptide chains could be built, except the C-terminal TETSQVAPA purification tag and the first nine N-terminal residues (QSVNDPGNM) in chains B, C, D and E. Furthermore, clear electron density is visible for benzamidine molecules, one of which occupies every orthosteric ligand binding site, as well as 11 out of the $15 \mathrm{~N}$-linked glycosylation sites, the remaining four being located in the $\mathrm{N}$ terminal disordered regions of chains B-E. Glycans attached to Asn 149 in each chain were protected from endoglycosidase F1 cleavage due to extensive interactions with the protein core, underlying their important structural role. Stereochemical properties of the model were assessed in $\operatorname{Coot}^{69}$ and Molprobity ${ }^{72}$. Protein geometry analysis revealed no Ramachandran outliers, with $96.98 \%$ residues in favoured regions and 3.02\% residues in allowed regions. Molprobity clash score after adding hydrogens is $5.74\left(100^{\text {th }}\right.$ percentile $)$ and the overall Molprobity score is $1.85\left(100^{\text {th }}\right.$ percentile $)$.

Sequence and structural alignments were performed in ClustalW ${ }^{73}$ and $\mathrm{SHP}^{74}$, respectively. Protein interfaces were analysed using the PDBePISA web server at the European Bioinformatics Institute (http://www.ebi.ac.uk/pdbe/prot_int/pistart.html) ${ }^{75}$ and residue conservation was mapped onto the crystal structure using ProtSkin ${ }^{76}$. Electrostatic surface potential calculations were performed using the APBS Tools plug-in in PyMOL ${ }^{77}$ and pore/ tunnel dimensions were analysed using the Caver 3.0 software for a probe radius of $1.4 \AA^{78}$. Structural figures were prepared with the PyMOL Molecular Graphics System, Version 1.6, Schrödinger, LLC.

\section{Thermostability binding experiments}

The thermostability of detergent-solubilised constructs was determined by heating them over a range of temperatures for equal time periods and then measuring the reduction in the intensity of the monodisperse SEC profile for each sample ${ }^{79}$. With increasing temperature, an increased proportion of protein is denatured, aggregates and therefore lost from the monodisperse peak when the protein is subsequently run on SEC. Protein stability was evaluated by plotting the decay in peak UV absorbance against increasing temperature, for example to obtain a $50 \%$ melting temperature $\left(\mathrm{T}_{\mathrm{m}}\right)$. Purified $\mathrm{GABA}_{\mathrm{A}} \mathrm{R}-\beta 3_{\text {cryst }}$ protein at $0.05 \mathrm{mg} / \mathrm{ml}(20 \mathrm{nM})$ in $150 \mathrm{mM} \mathrm{NaCl}, 10 \mathrm{mM}$ HEPES pH 7.2, $0.007 \%$ DMNG (w/v), $0.0006 \% \mathrm{CHS}(\mathrm{w} / \mathrm{v})$ was separated into $50 \mu \mathrm{l}$ aliquots in PCR tubes, and heated at a range of temperatures from $30-80{ }^{\circ} \mathrm{C}$ for 1 hour. Samples were run on a high-performance liquid 
chromatography system with automated micro-volume loader (Shimadzu) through a Superdex 200 3.2/300 column (GE Healthcare) maintained in $300 \mathrm{mM} \mathrm{NaCl}, 10 \mathrm{mM}$ HEPES, $0.007 \%$ DMNG (w/v), $0.0006 \%$ CHS (w/v). Monodisperse peak reduction with increasing temperature was measured relative to an unheated control sample maintained at 4 ${ }^{\circ} \mathrm{C}$.

Importantly, because some drugs thermostabilise detergent-solubilised proteins upon binding ${ }^{79}$, the above thermostability assay also offers an efficient strategy to measure protein sensitivity to drugs in the detergent-solubilised environment, and therefore to probe the effects of detergent on protein structural integrity, and to evaluate the structural integrity of engineered constructs. Purified $\mathrm{GABA}_{\mathrm{A}} \mathrm{R}-\beta 3_{\text {cryst }}$ was aliquoted into PCR tubes, supplemented with ligand at a range of concentrations and heated at $66^{\circ} \mathrm{C}$ (the temperature at which the monodisperse peak was reduced by $70 \%$ ) for 1 hour. Afterwards samples were run on a high-performance liquid chromatography system with automated micro-volume loader (Shimadzu) through a Superdex 200 3.2/300 column (GE Healthcare) maintained in $300 \mathrm{mM} \mathrm{NaCl}, 10 \mathrm{mM}$ HEPES, $0.007 \%$ DMNG (w/v), $0.0006 \%$ CHS (w/v). Drug doseresponse curves were generated by plotting UV absorbance against drug concentration.

\section{Fluorescence displacement assay}

Fluorescence emission spectra from 490-560 nm for the fluorescent ligand 1aminoanthracene (1-AMA) at $5 \mu \mathrm{M}$, in the presence of $0.3 \mu \mathrm{M} \mathrm{GABA} A-\beta 3_{\text {cryst }}$ and increasing concentrations of the anaesthetic etomidate, were measured using a Varian Cary Eclipse Fluorescence spectrophotometer, with excitation at $400 \mathrm{~nm}$ (5 nm slit width).

\section{Electrophysiology}

Electrophysiological recordings were made from HEK293S-GnTI- cells stably expressing $\mathrm{GABA}_{\mathrm{A}} \mathrm{R}-\beta 3_{\text {cryst }}$ using a Nanion Port-a-Patch (Nanion) ${ }^{80}$ or from HEK293T cells transiently transfected with $\mathrm{GABA}_{\mathrm{A}} \mathrm{R}-\beta 3_{\text {cryst }}$ using a traditional patch-clamp set-up. The internal pipette solution contained (mM): $140 \mathrm{KCl}, 2 \mathrm{MgCl}_{2}, 1 \mathrm{CaCl}_{2}, 10$ HEPES, 11 EGTA, and 2 ATP, pH $7.2(\approx 300$ mOsm $)$. The external saline solution contained $(\mathrm{mM})$ : $140 \mathrm{NaCl}, 4.7 \mathrm{KCl}, 1.2 \mathrm{MgCl}_{2}, 2.5 \mathrm{CaCl}_{2}, 10$ HEPES, and 11 D-Glucose, pH $7.4(\approx 300$ mOsm). An Axopatch 200B amplifier (Axon instruments) was used to record whole-cell currents voltage-clamped at $-40 \mathrm{mV}$. Recording chips with pore resistances of 3-5 $\mathrm{M} \Omega$ were used for Nanion recordings, or patch electrodes were pulled from thick-walled borosilicate glass (Harvard Electronics). For Nanion recordings, $20 \mu \mathrm{l}$ of a HEK293S-GnTI ${ }^{-}$cell suspension in external saline solution was manually pipetted over the chip pore and the Nanion suction protocol was applied to obtain a giga-seal and subsequent whole-cell configuration. Five microliters of agonist drug (histamine or benzamidine) were manually pipetted at 5 -fold final concentration $(50 \mathrm{mM})$ into the $20 \mu \mathrm{l}$ saline bath. Subsequently 6.25 $\mu \mathrm{l}$ of agonist drug + channel blocker (fipronil or picrotoxin) was manually pipetted at 5-fold concentration ( $50 \mathrm{mM}$ for agonist, $50 \mu \mathrm{M}$ for blocker) into the $25 \mu \mathrm{l}$ saline bath. For the traditional patch-clamp set-up, drug-solutions were applied using a rapid solution changer (model RSC-200; Biological Science Instruments). Maximal whole-cell agonist evoked currents were in the range $0.2-1 \mathrm{nA}$. Data was recorded in several minute acquisition 
epochs into pClamp 10.0 software on a computer via a Digidata 1322A (Axon instruments) sampling at $200 \mu$ s intervals.

\section{Extended Data}

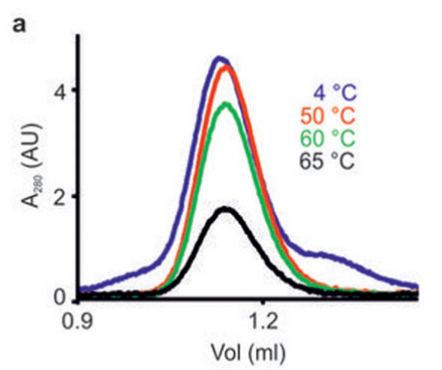

d

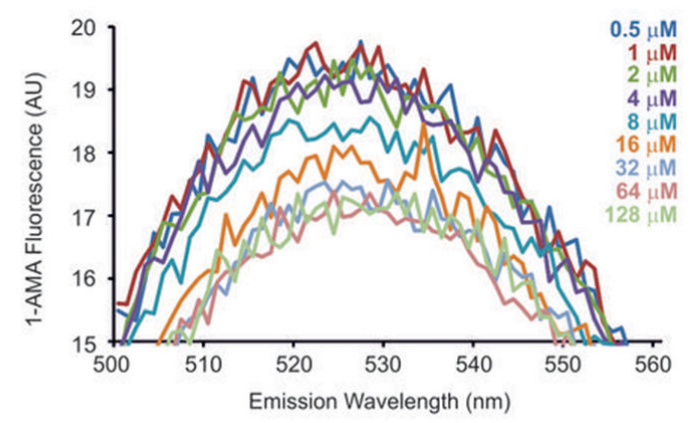

f

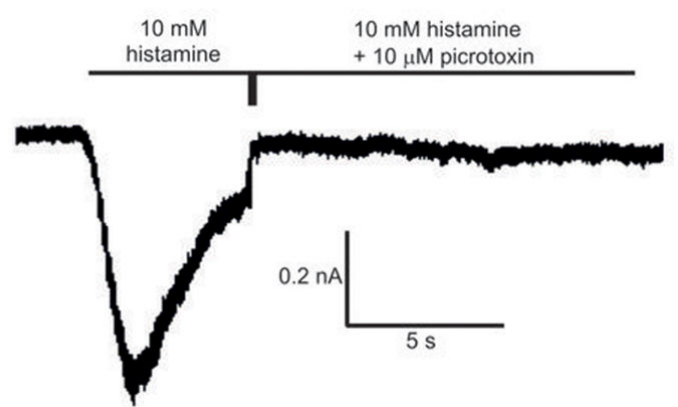

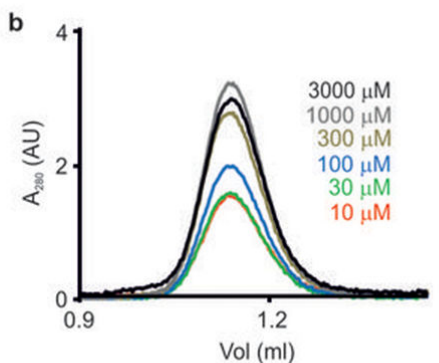

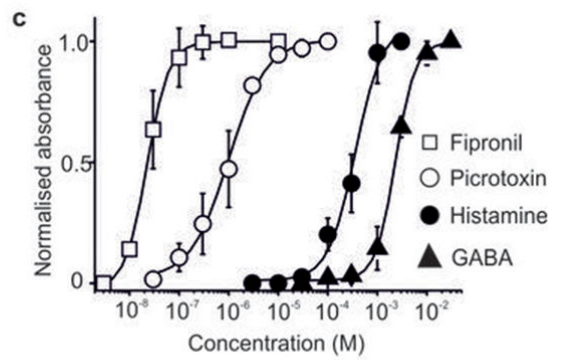

。

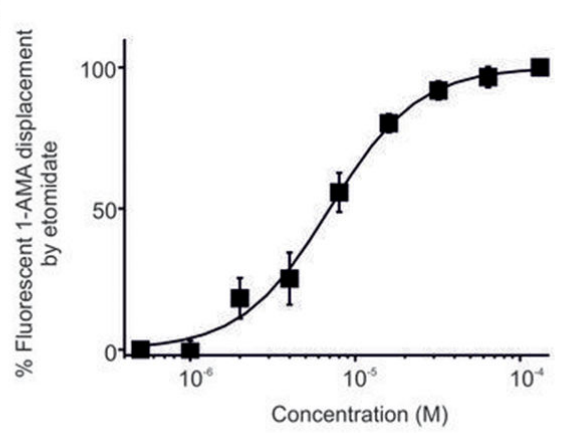

g

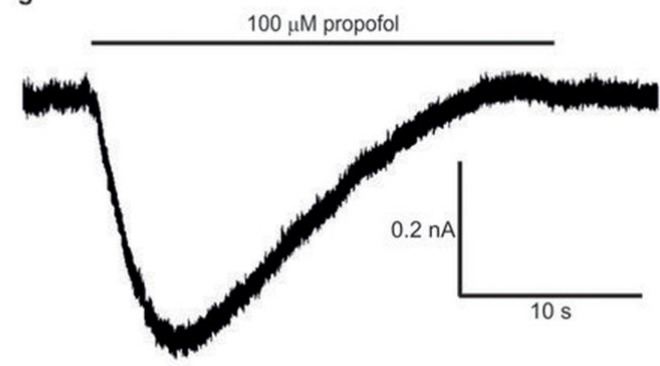

Extended Data Figure 1. Ligand binding to $\mathbf{G A B A _ { A }} \mathbf{R}-\beta 3_{\text {cryst }}$ in detergent micelles and in HEK293T cells

a, Overlays of size-exclusion profiles for equal amounts of purified $G A B A_{A} R-\beta 3_{\text {cryst }}$ that were pre-heated at different temperatures for 1 hour in order to evaluate protein stability. $\mathbf{b}$, Overlays of size-exclusion profiles of purified $\mathrm{GABA}_{\mathrm{A}} \mathrm{R}-\beta 3_{\text {cryst }}$ heated at $66{ }^{\circ} \mathrm{C}(70 \%$ decay temperature) for 1 hour in the presence of increasing doses of histamine. Histamine binding protects (stabilises) the protein in accordance with its affinity, giving a doseresponse profile. c, Profiles of $\mathrm{GABA}_{\mathrm{A}} \mathrm{R}-\beta 3_{\text {cryst }}$ thermostabilisation in detergent micelles by four ligands. Values in brackets represent the $\mathrm{EC}_{50}$ of thermostabilisation. The assay was used to evaluate two channel blockers, the insecticide fipronil $(26 \pm 5 \mathrm{nM})$ and the convulsant picrotoxin $(900 \pm 480 \mathrm{nM})$, and two neurotransmitter agonists, GABA $(2.3 \pm 0.2$ $\mathrm{mM})$ and histamine $(400 \pm 150 \mu \mathrm{M})$. NOTE: the $\mathrm{GABA}_{\mathrm{A}} \mathrm{R}-\beta 3_{\text {cryst }}$ low sensitivity to GABA is in keeping with that observed for full-length homomeric $\mathrm{GABA}_{\mathrm{A}} \mathrm{R}-\beta 3$ receptors, which 
are also less sensitive than $\alpha \beta$ and $\alpha \beta \gamma$ heteromeric $\mathrm{GABA}_{\mathrm{A}} \mathrm{Rs}^{81}$. d, e Displacement of bound 1-aminoanthracene (1-AMA) from $\mathrm{GABA}_{\mathrm{A}} \mathrm{R}-\beta 3_{\text {cryst }}$ by the anaesthetic etomidate. The fluorescent ligand 1-AMA $(5 \mu \mathrm{M})$ in the presence of $0.3 \mu \mathrm{M} \mathrm{GABA}_{\mathrm{A}} \mathrm{R}-\beta 3_{\text {cryst }}$ experienced an increase in fluorescence (due to binding in the hydrophobic anaesthetic pocket ${ }^{82}$ ) that was displaced by increasing concentrations of etomidate; $50 \%$ maximal displacement occurs at 7.1 $\pm 1.1 \mu \mathrm{M}, \mathrm{n}=5$. Peak heights of single traces were measured as the average intensities of peak points between 519 and $533 \mathrm{~nm}$. Equivalent doses of etomidate with the fluorescent ligand 1-AMA $(5 \mu \mathrm{M})$ in the absence of $\mathrm{GABA}_{\mathrm{A}} \mathrm{R}-\beta 3_{\text {cryst }}$ did not displace (reduce) fluorescent signal (not shown). f-g, HEK293T whole-cell patch-clamp recordings of the natural ligand histamine (f) activating an inward current through $\mathrm{GABA}_{\mathrm{A}} \mathrm{R}-\beta 3_{\text {cryst }}$, subsequently blocked by the channel-blocker picrotoxin (fipronil also blocked histamine currents, not shown) and of the anaesthetic propofol activating an inward current through $\mathrm{GABA}_{\mathrm{A}} \mathrm{R}-\beta 3_{\text {cryst }}(\mathbf{g})$. All error bars are s.e.m. 


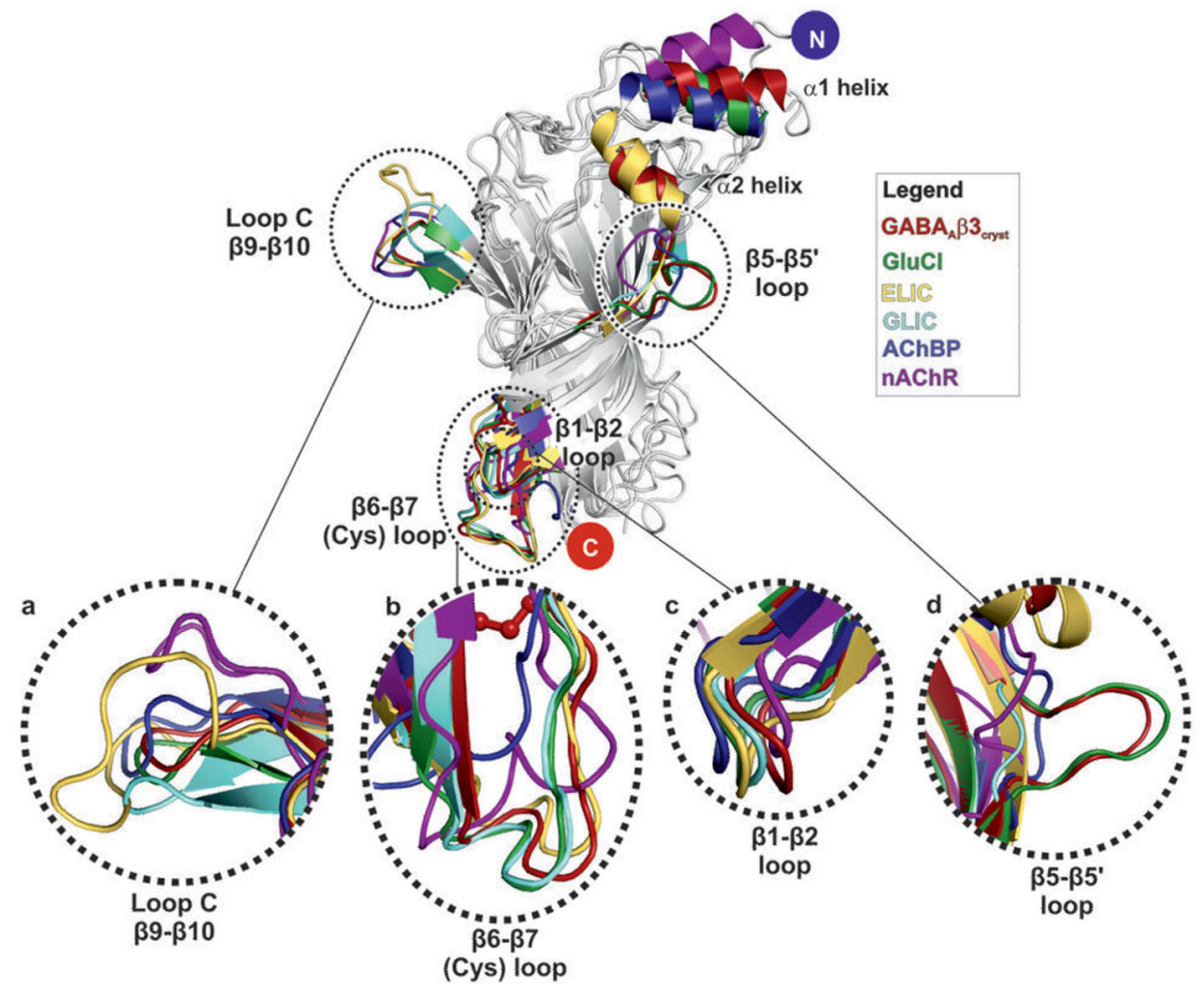

e

\begin{tabular}{|c|c|c|c|c|}
\hline $\begin{array}{l}\text { Reference structure } \\
\text { (chain/residue range/PDB ID) }\end{array}$ & $\begin{array}{l}\text { Moving structure } \\
\text { (chain/residue range/PDB ID) }\end{array}$ & $\begin{array}{l}\text { Equivalent } \\
\text { Capositions }\end{array}$ & $\begin{array}{l}\text { Identical residues } \\
\text { at equivalent } \\
\text { positions }\end{array}$ & $\begin{array}{l}\text { rmsd of equivalent } \mathrm{C \alpha} \\
\text { coordinates }(A)\end{array}$ \\
\hline $\begin{array}{c}\text { GABA } R-\beta 3_{\text {crst }} \text { ECD } \\
(A / 1-217 / 4 \text { COF) } \\
" \\
" \\
" \\
"\end{array}$ & $\begin{array}{l}\text { GluCI ECD (A/1-212/3RIF) } \\
\text { ELIC ECD (A/11-199/2VL0) } \\
\text { GLIC ECD (A / 5-193/4HFI) } \\
\text { AChBP (A / 1-205/1UX2) } \\
\text { nAChR closed ECD (A/1-210/2BG9) } \\
\text { nAChR open ECD (A/ 1-210/4AQ9) } \\
\text { nAChR closed ECD (A/1-210/4AQ5) }\end{array}$ & $\begin{array}{l}198 \\
163 \\
176 \\
185 \\
180 \\
185 \\
182\end{array}$ & $\begin{array}{l}73(36.9 \%) \\
42(25.8 \%) \\
37(21 \%) \\
39(21.1 \%) \\
37(20.6 \%) \\
37(20 \%) \\
33(18.1 \%)\end{array}$ & $\begin{array}{l}1.38 \\
1.55 \\
1.78 \\
2.14 \\
2.16 \\
2.31 \\
2.30\end{array}$ \\
\hline $\begin{array}{c}\text { GABA } R-\beta 3_{\text {cryst }} \text { TMD } \\
(A / 218-447 / 4 \text { COF) } \\
" \\
" \\
" \\
"\end{array}$ & $\begin{array}{l}\text { GluCI TMD (A/213-340/3RIF) } \\
\text { GLIC TMD (A / 194-315/ 4HFI) } \\
\text { ELIC TMD (A/ 200-316/2VLO) } \\
\text { nAChR closed TMD (A/211-437/2BG9) } \\
\text { nAChR open TMD (A / } 211-437 / 4 \text { AQ9) } \\
\text { nAChR closed TMD (A/211-437/4AQ5) }\end{array}$ & $\begin{array}{l}123 \\
121 \\
111 \\
110 \\
111 \\
109\end{array}$ & $\begin{array}{l}52(42.3 \%) \\
38(31.4 \%) \\
28(25.2 \%) \\
11(10.0 \%)^{*} \\
9(8.1 \%)^{*} \\
11(10.1 \%)^{*}\end{array}$ & $\begin{array}{l}0.97 \\
1.62 \\
2.14 \\
2.27 \\
2.41 \\
2.45\end{array}$ \\
\hline
\end{tabular}

* The aminoacid sequences in the M2 and M3 helices of the NAChR open and closed models (PDB IDs 4AQ5, 2BG9 and 4AQ9) appear to be out of register by 4 residues. As a result, the number of identical residues occupying equivalent positions in $n A C h R$ and $G A B A_{A} R-\beta 3_{\text {crnt }}$ is lower than expected from sequence alignment $(22 \%)$.

Extended Data Figure 2. Structural alignment of pLGIC extracellular domains and AChBP The top panel shows structures aligned to the $\mathrm{GABA}_{\mathrm{A}} \mathrm{R}-\beta 3_{\text {cryst }} \mathrm{ECD}$, viewed perpendicular to the five-fold pseudo-symmetry axis, from inside the extracellular vestibule. Colour coding: GABA ${ }_{A} R-\beta 3_{\text {cryst }}$ in red (PDB $4 \mathrm{COF}$ ); GluCla in green (PDB 3RIF); ELIC in yellow (PDB 2VL0); GLIC in cyan (PDB 4HFI); AChBP in dark blue (PDB 1UX2); $\mathrm{nAChR}$ in violet (PDB 2BG9). Four variable loop regions of functional significance for neurotransmitter binding, signal transduction and receptor assembly have been individually rotated to optimize viewing of the disparities between these structural elements. a, Loop C ( $\beta 9-\beta 10)$, capping the neurotransmitter binding site. b, Loop $\beta 6-\beta 7$ (Cys-loop in eukaryotic structures), important for ECD-TMD coupling and signal transduction. c, Loop $\beta 1-\beta 2$, important for ECD-TMD coupling and signal transduction. d, Loop $\beta 5-\beta 5^{\prime}$, important for subunit assembly at the ECD level. e, Table showing parameters of structural alignment between the $\mathrm{GABA}_{\mathrm{A}} \mathrm{R}-\beta 3_{\text {cryst }}$ extracellular (ECD) and transmembrane (TMD) domains, 
respectively, and equivalent regions in pLGICs as well as the acetylcholine binding protein (AChBP) from Lymnaea stagnalis. Superpositions were performed using the SHP programme (see Methods for details).
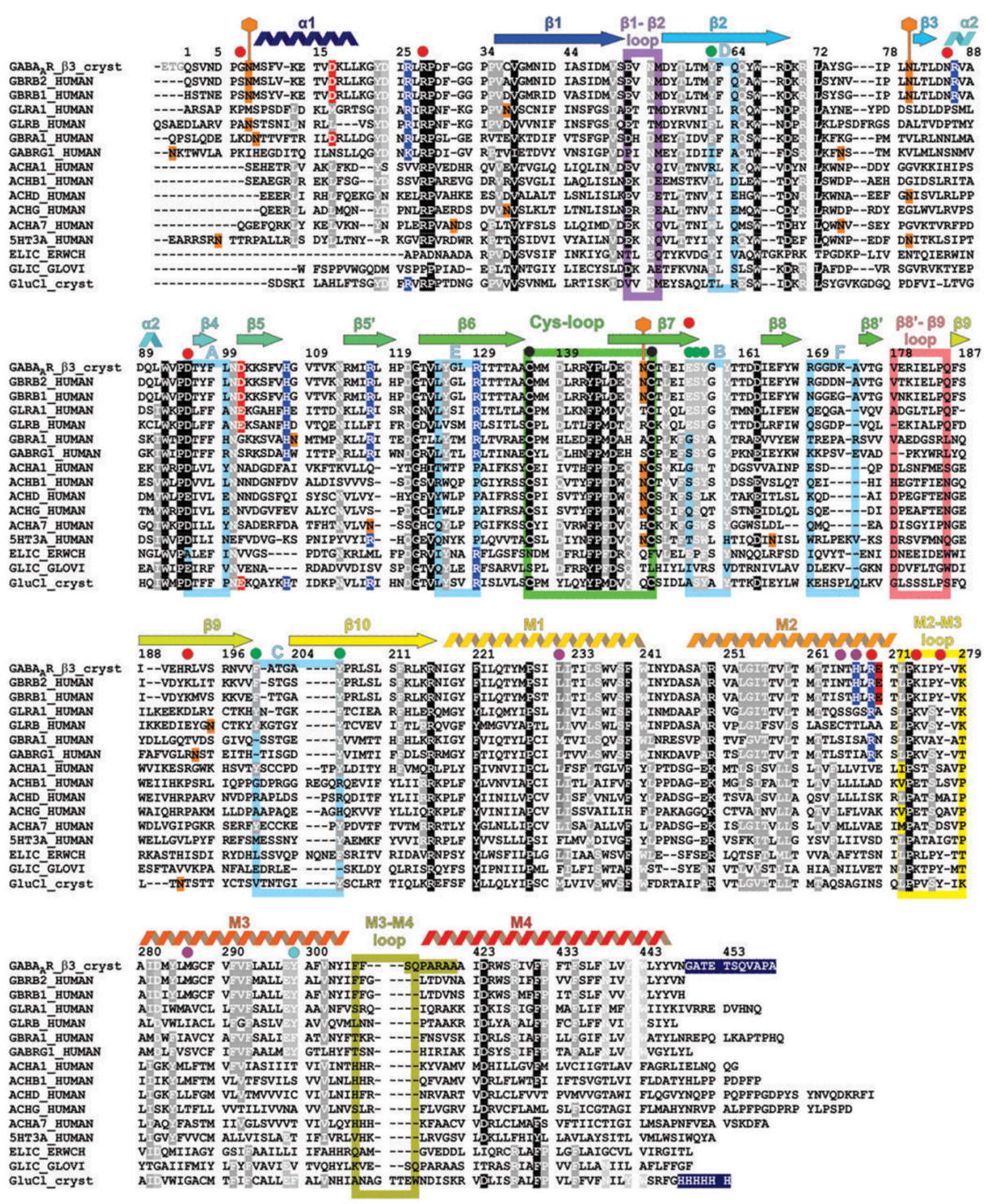

Extended Data Figure 3. Sequence alignment of $\operatorname{GABA}_{\mathbf{A}} \mathrm{R}-\boldsymbol{\beta 3}_{\text {cryst }}$ with representative human Cys-loop receptor family members and the other pLGICs crystallized to date (ELIC, GLIC and GluCla)

Residue conservation is indicated by black/grey highlights. Residues involved in intersubunit salt-bridges are highlighted in red/blue, sites of N-linked glycosylation are highlighted in orange. Sequence block-highlights indicate the classically-defined neurotransmitter-binding loops (A-F, in light cyan), as well as key loops discussed in the manuscript: $\beta 1-\beta 2$ in purple; $\beta 6-\beta 7$ (the Cys-loop) in dark green; $\beta 8^{\prime}-\beta 9$ loop in light red; M2-M3 loop in yellow; M3-M4 loop in mustard. Dots above the sequence mark residues linked to human diseases (red), binding of anaesthetics (violet), interactions with agonist 
benzamidine (green) and Tyr299, whose side chain conformation appears to contribute to the control of channel desensitisation (cyan). Orange hexagons indicate N-linked glycans observed in the $\mathrm{GABA}_{\mathrm{A}} \mathrm{R}-\beta 3_{\text {cryst }}$ structure. C-terminal residues on dark-blue background represent affinity purification tags. Secondary structure element colouring corresponds to Fig. 1c. The $\mathrm{GABA}_{\mathrm{A}} \mathrm{R}-\beta 3_{\text {cryst }}$ residue numbering, shown above the sequence, matches the mature isoform 1 (UniProt entry P28472 Gln26 becoming Gln1). Other sequences are from the following Uniprot entries: GBRB2, P47870; GBRB1, P18505; GLRA1, P23415; GLRB, P48167; GBRA1, P14867; GABRG1, Q8N1C3; ACHA1, P02708-2; ACHB1, P11230; ACHD, Q07001; ACHG, P07510; ACHA7, P36544; 5HT3A, P46098; ELIC, P0C7BY7; GLIC, Q7NDN8. GluCla sequence is from PDB ID: 3RIF. To keep the alignment as compact as possible, the following regions of poor conservation were removed: secretion signal sequences and cytoplasmic M3-M4 loop (as annotated in Uniprot) except for bacterial channels and GluCla; residues 184-192 (GLGPDGQGH) from ACHB1; residues 188-199 (KENRTYPVEWII) from ACHD; residues 187-194 (GQTIEWIF) from ACHG. 

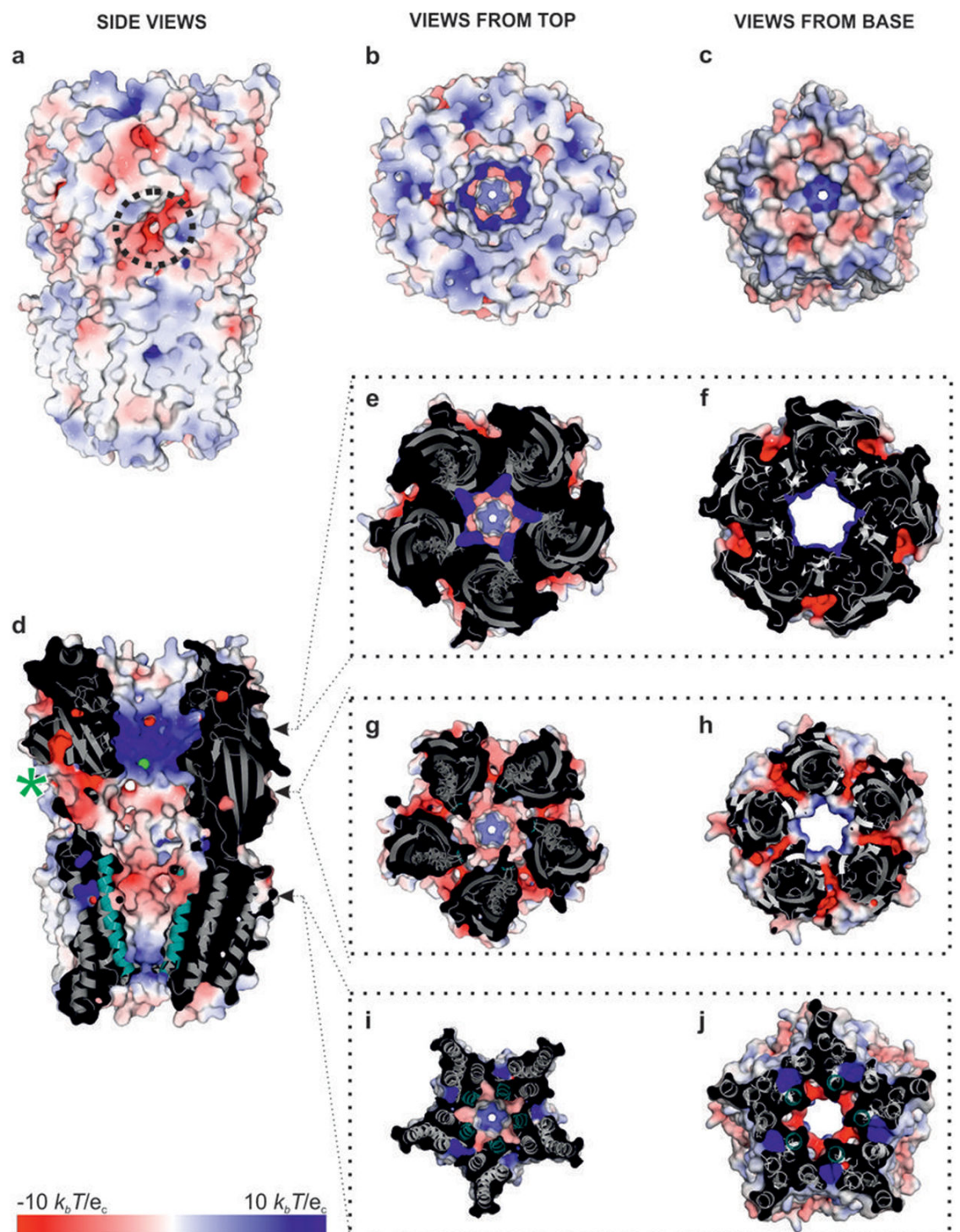

Extended Data Figure 4. Solvent-accessible surfaces of $G A B A_{A} R-\beta 3_{\text {cryst }}$ coloured by electrostatic potential

a, Outside view of the receptor, perpendicular to the 5-fold pseudo-symmetry axis. The exit point of an ECD side tunnel is indicated by a dotted circle (transversal sections in $\mathbf{g}-\mathbf{h}$ are at this level). b, View from the extracellular side, along the 5-fold pseudo-symmetry axis. c, View from the intracellular side, along the 5-fold pseudo-symmetry axis. The positively charged region surrounding the central pore originates from the dipoles of the M2 helices. $\mathbf{d}$, Longitudinal cross-section (interior cartoon coloured grey except for pore-lining helices in deep teal), showing electrostatic surface potential inside the pore and in the extracellular vestibule. Arrowheads indicate positions of the transverse cross-sections. A chloride ion bound within the positively charged vestibule belt is shown as a green sphere. The green asterisk marks the exit of a inter-subunit side-tunnel. e, f, Transverse section at level of the neurotransmitter binding site (negatively charged), observed from above and underneath. $\mathbf{g}$, 
$\mathbf{h}$, Transverse section at level of the ECD tunnels, negatively charged. $\mathbf{i}, \mathbf{j}$, Transverse section at level of the anaesthetic (etomidate) binding site, positively charged.
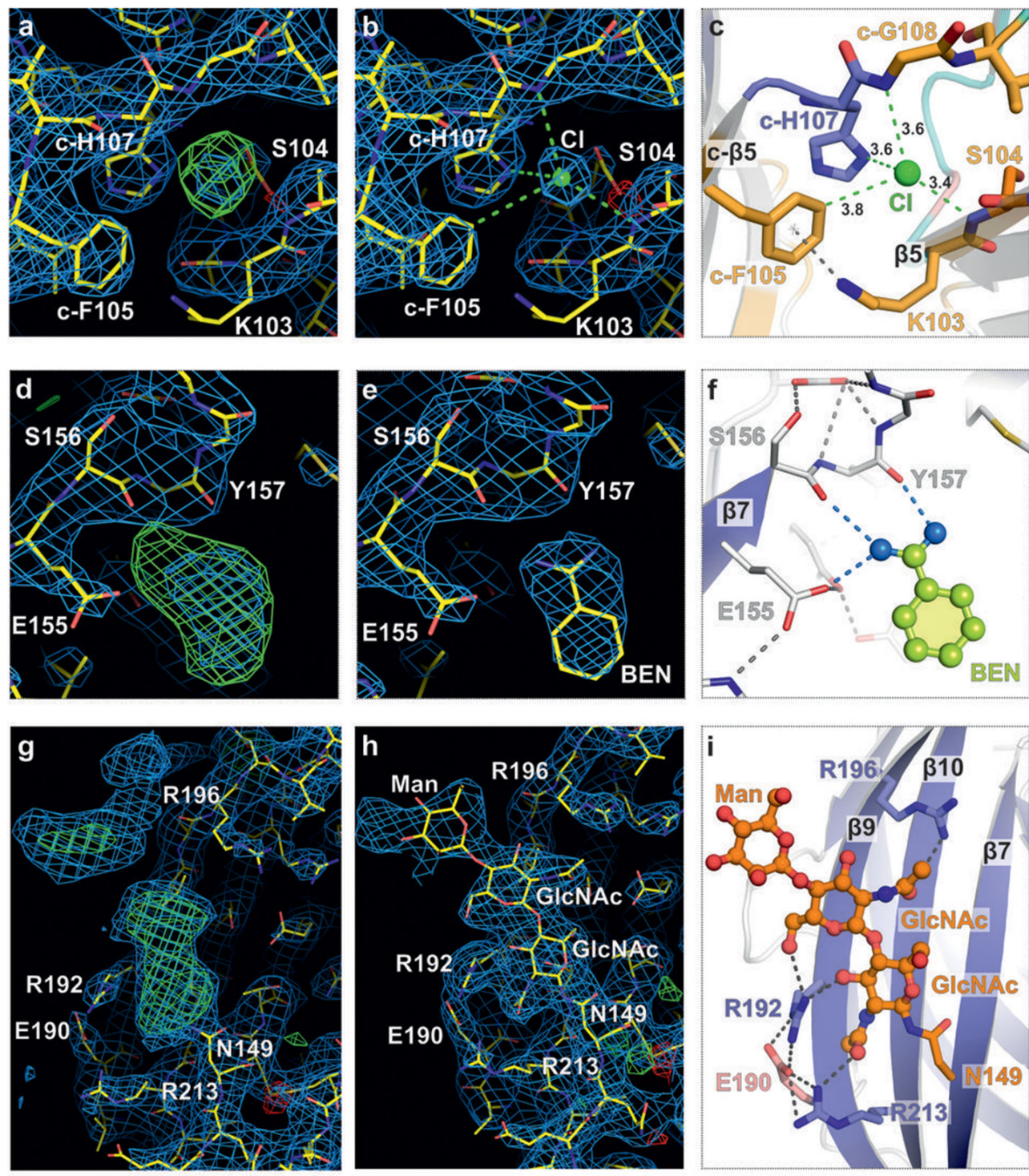

Extended Data Figure 5. Crystallographic quality control for non-protein elements in the $\mathbf{G A B A}_{\mathbf{A}} \mathbf{R}-\boldsymbol{\beta 3 _ { \text { cryst } }}$ structure

a-c, The anion binding site between ECD interfaces (corresponding to main text Fig. 2c). a, SigmaA-weighted $2 F_{o^{-}} F_{c}$ (blue, contoured at $1.5 \sigma$ ) and $F_{o}-F_{c}$ (green/red contoured at $+3 \sigma /$ $-3 \sigma$ ) electron density maps following autoBUSTER refinement in the absence of chloride.

b, The same electron density maps and contour levels following refinement in the presence of chloride. c, Final model, showing the chloride coordination sphere. d-f, Equivalent panels to the ones described above, for the benzamidine ligand bound to the neurotransmitter pocket. g-i, Equivalent panels to the ones described above, for the N-linked glycan at site 3 (Asn149) except that the contour level of the $2 F_{o}-F_{c}$ maps is $1 \sigma$. Dotted lines in $\mathbf{f}$ and $\mathbf{i}$ indicate contacts within hydrogen-bonding distance. 

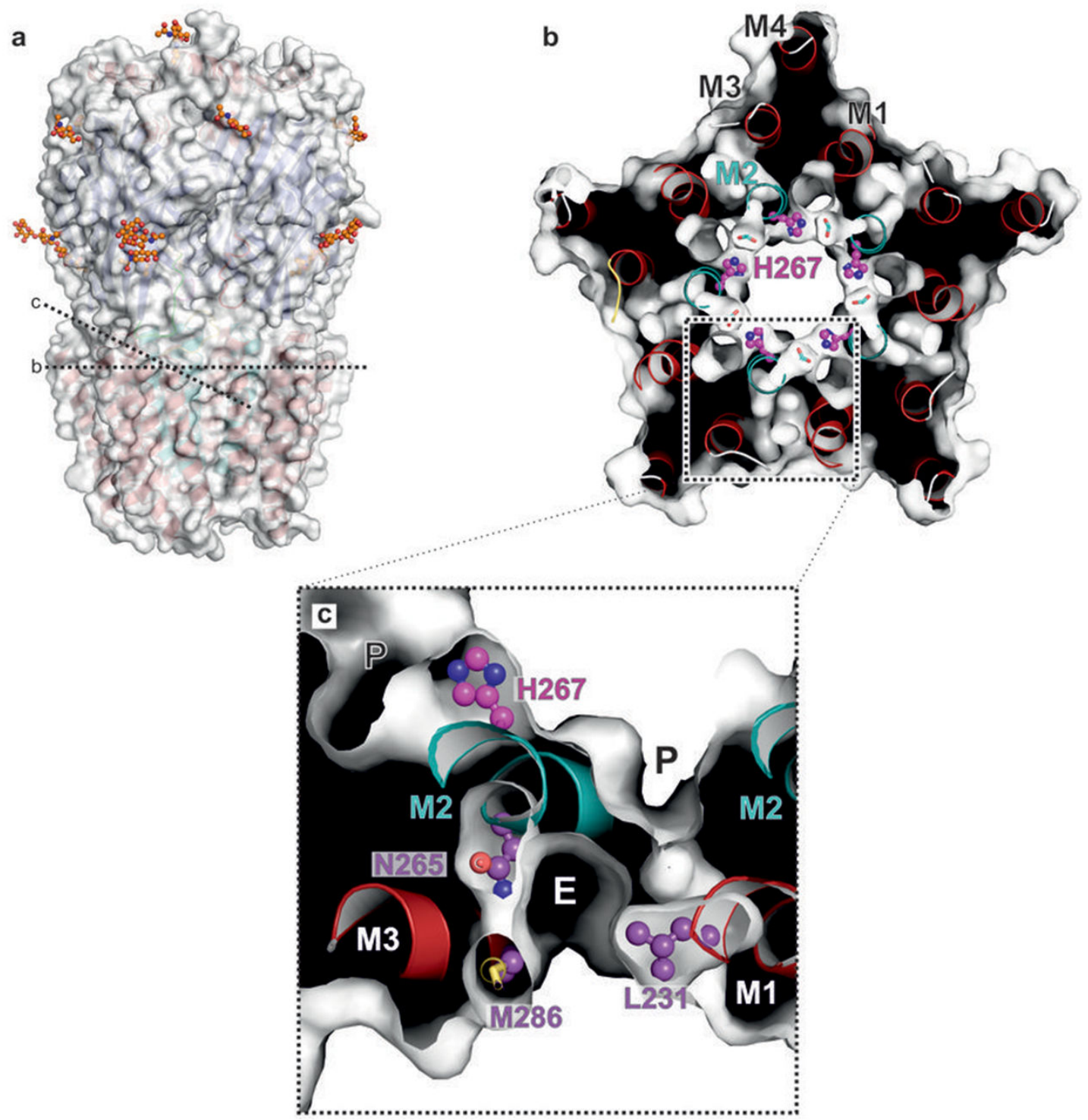

Extended Data Figure 6. Binding cavities for intravenous anaesthetics

a, Side view of a GABA $A_{A}$ - $\beta 3_{\text {cryst }}$ surface representation. Dotted lines indicate the planes of the transverse sections shown in $\mathbf{b}$ and $\mathbf{c}$. $\mathbf{b}$, Transverse section through the pentamer at the level of $17^{\prime}$ His (His 267), previously found to bind photolabelled propofol ${ }^{29}$. c, Close-up of tilted transverse section indicated in (a), revealing the putative anaesthetic binding pockets in $\mathrm{GABA}_{\mathrm{A}} \mathrm{R}-\beta 3_{\text {cryst }}$ in agreement with previous mutagenesis and photolabelling studies with etomidate $^{28}$ and propofol ${ }^{29}$ analogues. P: propofol binding site. E: etomidate binding site. 
a

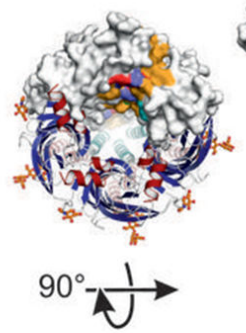

c

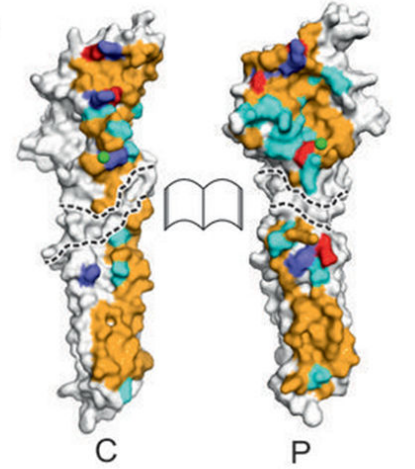

d

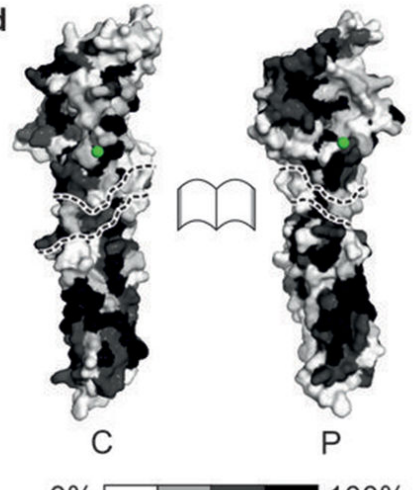

b

\begin{tabular}{|c|c|c|c|c|}
\hline \multirow{2}{*}{$\begin{array}{l}\text { Structure } \\
\text { (PDB ID) }\end{array}$} & \multicolumn{2}{|c|}{ Principal face } & \multicolumn{2}{|c|}{ Complementary face } \\
\hline & $\begin{array}{c}\text { Interface area } \\
\left(\AA^{2}\right)^{*} \\
{[E C D, T M D]}\end{array}$ & $\begin{array}{c}\Delta G^{S+}(\mathrm{kcal} / \mathrm{mol}) \\
{[E C D, T M D]}\end{array}$ & $\begin{array}{c}\text { Interface area } \\
\left(\AA^{2}\right)^{*} \\
{[E C D, T M D]}\end{array}$ & $\begin{array}{c}\Delta G^{S+} \\
(k c a l / m o l) \\
{[E C D, T M D]}\end{array}$ \\
\hline $\begin{array}{l}\text { GABA }_{A} R-B 3_{\text {cryst }} \\
\text { (4COF) }\end{array}$ & $\begin{array}{c}2560.7 \\
{[1418.2,1027.2]}\end{array}$ & $\begin{array}{c}-17.6 \\
{[-7.4,-9.7]}\end{array}$ & $\begin{array}{c}2626.8 \\
{[1499.6,1032.5]}\end{array}$ & $\begin{array}{c}-18.2 \\
{[-7.4 /-10.8]}\end{array}$ \\
\hline GluCl (3RIF) & $\begin{array}{c}2296.0 \\
{[1295.4,899.5]}\end{array}$ & $\begin{array}{c}-13.6 \\
{[-4.0,-8.6]}\end{array}$ & $\begin{array}{c}2421.7 \\
{[1391.2,937.5]}\end{array}$ & $\begin{array}{c}-8.8 \\
{[1.6,-9.9]}\end{array}$ \\
\hline GLIC (4HFI) & $\begin{array}{c}2220.1 \\
{[942.1,1198.9]}\end{array}$ & $\begin{array}{c}-12.9 \\
{[-0.2,-11.7]}\end{array}$ & $\begin{array}{c}2124.3 \\
{[888.5,1151.4]}\end{array}$ & $\begin{array}{c}-14.9 \\
{[-2.0,-12.6]}\end{array}$ \\
\hline ELIC (2VLO) & $\begin{array}{c}2588.2 \\
{[1244.8,1263.1]}\end{array}$ & $\begin{array}{c}-16.8 \\
{[-3.1,-12.8]}\end{array}$ & $\begin{array}{c}2467.7 \\
{[1184.8,1216.9]}\end{array}$ & $\begin{array}{c}-10.9 \\
{[-0.4,-10.4]}\end{array}$ \\
\hline $\begin{array}{l}\text { nAChR closed } \\
\text { (2BG9) }\end{array}$ & $\begin{array}{c}1623.3 \\
{[739.9,868.1]}\end{array}$ & $\begin{array}{c}-6.4 \\
{[2.3,-8.3]}\end{array}$ & $\begin{array}{c}1592.6 \\
{[708.8,864.8]}\end{array}$ & $\begin{array}{c}-13.9 \\
{[-5.2,-8.9]}\end{array}$ \\
\hline $\begin{array}{l}\text { nAChR open } \\
\text { (4AQ9) }\end{array}$ & $\begin{array}{c}1830.7 \\
{[911.3,709.8]}\end{array}$ & $\begin{array}{c}-7.6 \\
{[2.4,-7.3]}\end{array}$ & $\begin{array}{c}1835.0 \\
{[885.6,716.8]}\end{array}$ & $\begin{array}{c}-13.6 \\
{[-5.5,-7.4]}\end{array}$ \\
\hline $\begin{array}{l}\text { nAChR closed } \\
\text { (4AQ5) }\end{array}$ & $\begin{array}{c}1708.9 \\
{[809.3,685.8]}\end{array}$ & $\begin{array}{c}-7.4 \\
{[2.8,-7.6]}\end{array}$ & $\begin{array}{c}1694.8 \\
{[797.6,676.8]}\end{array}$ & $\begin{array}{c}-12.7 \\
{[-5.6,-6.7]}\end{array}$ \\
\hline AChBP (1UX2) & 1375.6 & -5.2 & 1366.5 & -3.9 \\
\hline
\end{tabular}

* Buried surface area, calculated using PISA ${ }^{75}$.

$\dagger \Delta G^{s}$ (solvation energy gain at complex formation) is the change of the solvation energy of a subunit due to the interface formation, in $\mathrm{kcal} / \mathrm{M}$, calculated using PISA ${ }^{75}$.

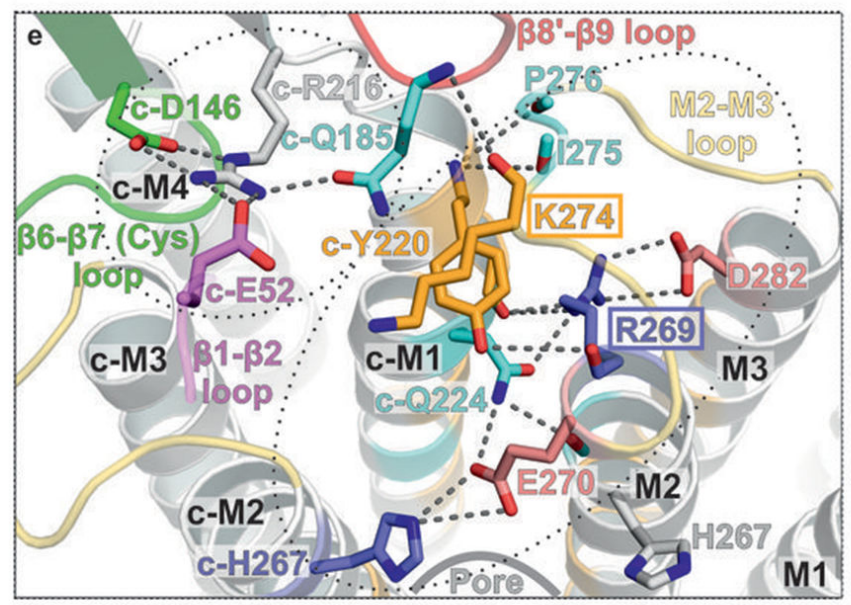

Extended Data Figure 7. Assembly interfaces between GABA $\mathbf{A}-\beta 3_{\text {cryst }}$ subunits

a, Top and side (from the vestibule) view of two $\mathrm{GABA}_{\mathrm{A}} \mathrm{R}-\beta 3_{\text {cryst }}$ neighbouring subunits, highlighting the nature of inter-subunit contacts between the "principal" $(\mathrm{P})$ face of one subunit and "complementary" (C) face of the next (box indicates the region enlarged in e). Residues involved in salt-bridges are coloured purple and red, those forming putative hydrogen-bonds in cyan and residues forming van der Waals contacts are in orange. b, Analysis of the inter-subunit interfaces between the ECDs and the TMDs. Values shown correspond to the most extensive inter-subunit interface in each PDB entry. The ECD was defined from the N-terminus up to one residue C-terminal of the conserved Arg at the end of $\beta 10$ strands in all pLGICs (Arg 216 in $\mathrm{GABA}_{\mathrm{A}} \mathrm{R}-\beta 3_{\text {cryst }}$ ). The TMD was defined as all residues beyond this point. c, "Open book" view of the inter-subunit interfaces (subunits were rotated $126^{\circ}$ outwards around their long axis, relative to their side orientation in a), with surfaces coloured by the nature of interactions. Dotted lines delineate the trajectory of 
an inter-subunit side-tunnel. d, "Open book" view (as above) of the inter-subunit interfaces with surface shaded by degree of conservation among $\mathrm{GABA}_{\mathrm{A}} \mathrm{R}$ and GlyR family members, revealing that key determinants of specificity are located largely in the ECDs where conservation is lower (Extended Data Fig. 7d). e, Top down view at the ECD-TMD interface level, showing key interactions within a single ECD (small oval) and between subunits (large oval). Grey dashed lines indicate putative hydrogen-bonds and salt-bridges. Boxed residues mark positions of disease mutations discussed in main text.
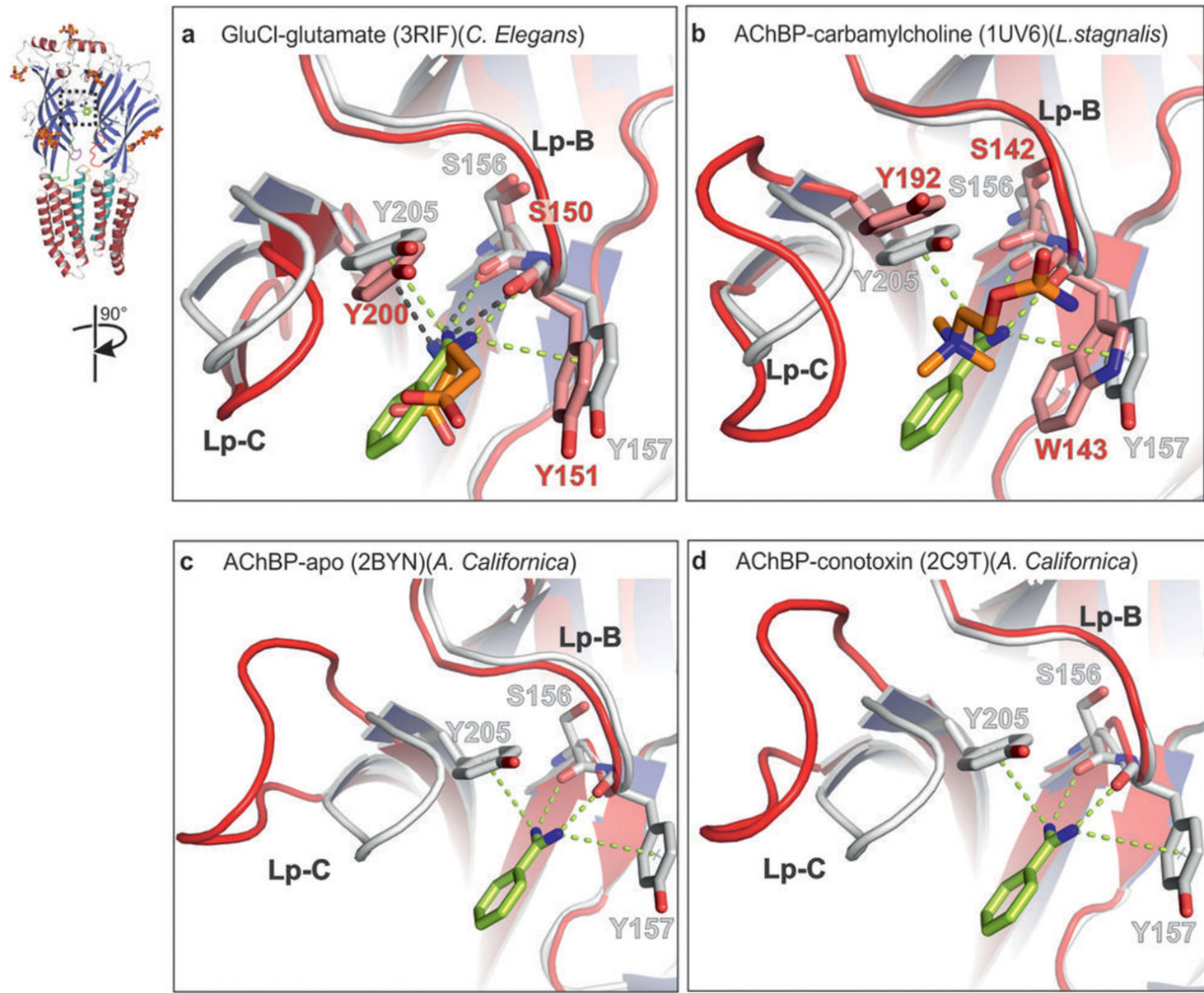

Extended Data Figure 8. Comparison of the $\beta 9-\beta 10$ (loop C) conformation, the agonist-binding site and the ligand orientation in $G_{A B} A_{A} R-\beta 3_{\text {cryst }}$ and equivalent GluCla and AChBP regions $\mathrm{GABA}_{\mathrm{A}} \mathrm{R}-\beta 3_{\text {cryst }}$ is shown in grey (with blue strands) and its agonist benzamidine in green. Selected $\mathrm{N}$ and $\mathrm{O}$ atoms are in blue and red, respectively. a, Structural alignment of $\mathrm{GABA}_{\mathrm{A}} \mathrm{R}-\beta 3_{\text {cryst }}$ and GluCla (PDB ID: $3 \mathrm{RIF}$, red backbone, with its agonist glutamate in orange); b, Structural alignment of $\mathrm{GABA}_{\mathrm{A}} \mathrm{R}-\beta 3_{\text {cryst }}$ and AChBP (PDB ID: $1 \mathrm{UV} 6$, red backbone) with agonist carbamylcholine bound (orange backbone); c, Structural alignment of $\mathrm{GABA}_{\mathrm{A}} \mathrm{R}-\beta 3_{\text {cryst }}$ and $\mathrm{AChBP}$ (PDB ID: $2 \mathrm{BYN}$, red backbone) in apo form; $\mathbf{d}$, Structural alignment of $\mathrm{GABA}_{\mathrm{A}} \mathrm{R}-\beta 3_{\text {cryst }}$ and $\mathrm{AChBP}$ (PDB ID: $2 \mathrm{C} 9 \mathrm{~T}$, red backbone) in an inhibitor toxin bound form (the toxin was excluded for clarity). Key binding residues from loop B and loop $\mathrm{C}$ are presented to highlight interactions with nitrogen atoms. In both a and $\mathbf{b}$, the $\beta 9$ - 
$\beta 10$ strand of $G A B A_{A} R-\beta 3_{\text {cryst }}$ adopts a similar conformation to the closed loop from GluCla-glutamate or AChBP-carbamylcholine. In both $\mathbf{c}$ and d, where AChBPs lack agonists, loop $\mathrm{C}$ is in an extended, open conformation different from its equivalent in $\mathrm{GABA}_{\mathrm{A}} \mathrm{R}-\beta 3_{\text {cryst }}$. Structural alignments were performed using SHP (see Methods).

\begin{tabular}{|c|c|c|c|c|c|c|c|}
\hline \multirow{2}{*}{$\begin{array}{l}\text { Structure } \\
\text { (PDB ID) }\end{array}$} & \multicolumn{6}{|c|}{ ECD-TMD interface } & \multirow{2}{*}{$\begin{array}{c}\text { TMD } \\
\text { rotation } \\
\text { angle }\left({ }^{\circ}\right)^{9}\end{array}$} \\
\hline & Interface area $\left(A^{2}\right)^{\dagger}$ & $\begin{array}{c}\Delta^{\prime} \mathrm{G}^{\ddagger} \\
(\mathrm{kcal} / \mathrm{mol})\end{array}$ & $\begin{array}{l}\text { N residues* } \\
\text { (ECD/TM) }\end{array}$ & $\mathrm{NH}^{5}$ & $N S B^{6}$ & $\begin{array}{c}\mathrm{NudW}^{5} \\
\text { (ECD/TM) }\end{array}$ & \\
\hline $\begin{array}{l}\text { GABA } A_{A} R-B 3_{\text {const }}(4 C O F) \\
\text { GluCl }(3 R \text { ) } \\
\text { GLIC (4HFI) } \\
\text { ELIC (2VLO) } \\
\text { nAChR open }(4 A Q 9)^{ \pm} \\
\text {nAChR closed }(4 A Q 5)^{ \pm}\end{array}$ & $\begin{array}{l}689.1 \\
673.1 \\
747.2 \\
590.0 \\
692.4 \\
664.8\end{array}$ & $\begin{array}{l}-10.0 \\
-12.0 \\
-7.1 \\
-11.9 \\
-10.8 \\
-9.9\end{array}$ & $\begin{array}{l}14 / 21 \\
13 / 24 \\
13 / 20 \\
15 / 17 \\
17 / 19 \\
16 / 19\end{array}$ & $\begin{array}{c}6 \\
7 \\
10 \\
6 \\
5 \\
3\end{array}$ & $\begin{array}{l}0 \\
0 \\
0 \\
0 \\
1 \\
1\end{array}$ & $\begin{array}{l}9 / 17 \\
5 / 118 \\
6 / 13 \\
10 / 13 \\
12 / 15 \\
12 / 16\end{array}$ & $\begin{array}{c}0.0 \\
6.35 \\
15.15 \\
20.61 \\
9.65 \\
9.71\end{array}$ \\
\hline
\end{tabular}

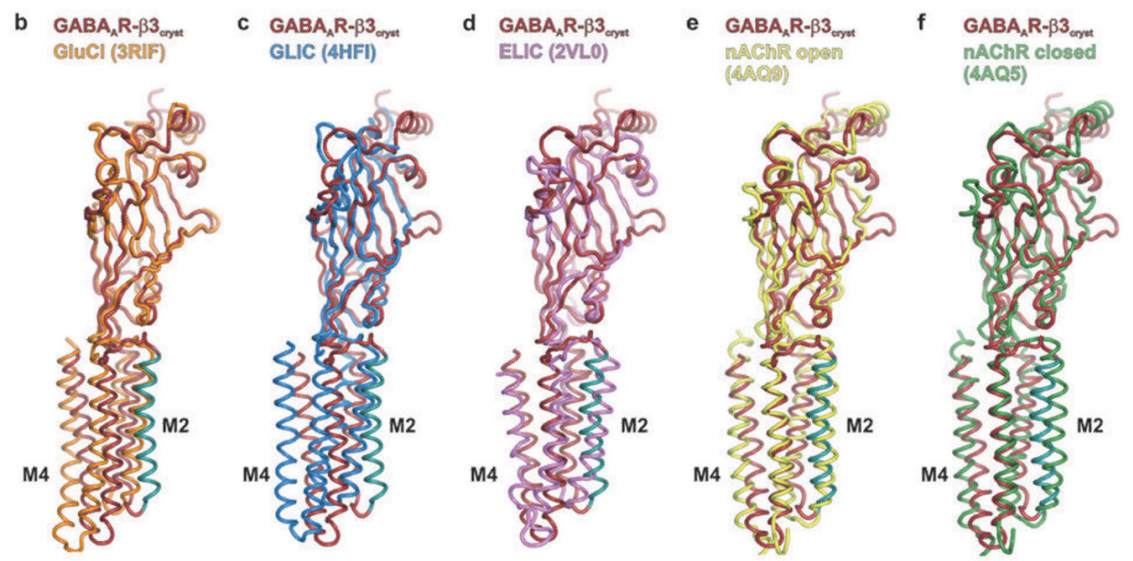

g

\begin{tabular}{|c|c|c|c|c|}
\hline $\begin{array}{l}\text { Position along } \\
\text { GABA } A_{A} R 3_{\text {cyst }} \text { M2 helix }\end{array}$ & $\begin{array}{l}\text { GABA } R \text { R- } \beta 3_{\text {cryst }} \\
\text { pore diameter } \\
\text { (A) }\end{array}$ & $\begin{array}{l}\text { Position along } \\
\text { GluCl (3RIF) M2 helix }\end{array}$ & $\begin{array}{l}\text { GluCl (3RIF) pore } \\
\text { diameter (A) }\end{array}$ & $\begin{array}{l}\text { GABA } A_{\alpha} R-\beta 3_{\text {cyss }}, C \alpha \\
\text { displacement }(A) \text {. } \\
\text { Inwards (-, red), } \\
\text { outwards }(+, \text { blue). }\end{array}$ \\
\hline E270, 20' & 14.90 & S265, 20' & 13.81 & -0.64 \\
\hline R269, $19^{\prime}$ & - & N264, $19^{\prime}$ & - & -0.69 \\
\hline ¿268, 18' & - & $1263,18^{\prime}$ & & -0.66 \\
\hline H267, 17' & 11.79 & G262, 17 & 14.82 & +1.49 \\
\hline T266. 16' & - & A261, 16' & 14.02 & $\begin{array}{l}+1.60 \\
+1.00\end{array}$ \\
\hline N265. 15' & - & $\begin{array}{l}\text { S260. } 15^{\prime} \\
\text { S2010 }\end{array}$ & : & $\begin{array}{l}+1.11 \\
+1.11\end{array}$ \\
\hline $1264,14^{\prime}$ & - & Q259. 14' & . & +1.12 \\
\hline T263, 13' & 14.11 & A258, 13' & 10.49 & +1.16 \\
\hline T262, 12' & - & T257, 12' & 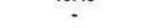 & +1.19 \\
\hline $\mathrm{M} 261,11^{\prime}$ & - & M256, 11' & . & +0.90 \\
\hline T260, $10^{\prime}$ & - & T255, $10^{\circ}$ & : & $\begin{array}{l}+0.78 \\
+0\end{array}$ \\
\hline L259, 9' & 13.32 & $\begin{array}{l}\text { L254, 9' } \\
\text { L25, }\end{array}$ & 7.25 & $\begin{array}{r}+0.76 \\
+0.76\end{array}$ \\
\hline V258, 8 & - & โ253, 8, & . & +0.75 \\
\hline T257.7 & - & T252. $7^{\prime}$ & : & $\begin{array}{l}+.68 \\
+0.68\end{array}$ \\
\hline T256. 6' & 10.48 & T251, 6' & 8.25 & +0.44 \\
\hline 1255,5 & - & V 250,5 & . & +0.41 \\
\hline G254, 4' & - & $\mathrm{G} 249,4^{\prime}$ & - & $\begin{array}{r}+.41 \\
+0.58\end{array}$ \\
\hline ᄂ253, 3 & - & L248, $3^{\prime}$ & . & +0.13 \\
\hline A252, 2, & 8.15 & T247, 2, & 6.63 & 0.05 \\
\hline V 251,1 & - & V 246,1 & 0.0 & -0.38 \\
\hline R250, $0^{\prime}$ & 5 & R245, $0^{\prime}$ & . & $\begin{array}{l}-0.70 \\
-0.71\end{array}$ \\
\hline A249, $1^{+}$ & - & A244, -1 & - & -0.81 \\
\hline A248, -2, & 3.15 & P243, -2, & 4.95 & -0.92 \\
\hline S247, - $3^{\prime}$ & - & $1242,-3$ & 4.0 & -1.16 \\
\hline
\end{tabular}

Extended Data Figure 9. Analysis of ECD-TMD interfaces and pore-lining M2 helices

a, Comparative analysis of ECD-TMD interfaces in pLGIC structures reported to date. Values correspond to chain A in each PDB entry. The ECD/TMD boundaries were set between the two residues C-terminal from the Arg that ends the $\beta 10$ strands in all pLGICs (Arg 216 in $\mathrm{GABA}_{\mathrm{A}} \mathrm{R}-\beta 3_{\text {cryst }}$, see sequence alignment in Extended Data Fig. 3). b-f, $\mathrm{GABA}_{\mathrm{A}} \mathrm{R}-\beta 3_{\text {cryst }}$ is shown in red (except the $\mathrm{M} 2$ helix, in teal). Its ECD was structurally aligned with equivalent regions of GluCla (PDB ID: 3RIF, in b), GLIC (PDB ID: 4HFI, in c), ELIC (PDB ID: 2VLO, in d), nAChR open (PDB ID: 4AQ9, in e) and nAChR closed 
(PDB ID: 4AQ5 in f). Alignments reveal relative variations in the ECD-TMD orientation. Structural alignments were performed using SHP (see Methods). g, Comparative analysis of $\mathrm{M} 2$ helix curvature, based on individual $\mathrm{Ca}$ positions, and pore diameter in $\mathrm{GABA}_{\mathrm{A}} \mathrm{R}$ $\beta 3_{\text {cryst }}$ (desensitised conformation) versus GluCl (PDB ID: 3RIF, open conformation). Residues whose side chains line the pore are highlighted in bold. Pore diameters were calculated at the level of $\mathrm{Ca}$ atoms, using Caver (see Methods). Legend: ${ }^{\dagger}$ Calculated as the difference between total accessible surface areas of isolated and interfacing structures, divided by two, using PISA. ${ }^{+}$Indicates the solvation free energy gain upon formation of the interface. The value is calculated as difference in total solvation energies of isolated and interfacing structures, using PISA. ${ }^{*} N$ residues: number of residues involved in ECD-TMD interactions. ${ }^{\S} \mathrm{NH} / \mathrm{NSB} / \mathrm{NvdW}$ : number of putative $\mathrm{H}$-bonds, salt bridges and additional van der Waals interactions that contribute to the ECD-TMD interface. "Rotation of TMD relative to the equivalent region in $\mathrm{GABA}_{\mathrm{A}} \mathrm{R}-\beta 3_{\text {cryst }}$, around the inter-domain "effective hinge axis", following superposition of the A-chain ECDs (calculated using DynDom, http:// fizz.cmp.uea.ac.uk/dyndom/). ${ }^{ \pm}$The apparent register shift in the M2 and M3 helices (and connecting M2-M3 loop, which forms a large part of the ECD-TMD interface) in currently available nAChR models may impact on the values shown.

\section{Extended Data Table 1}

Crystallographic data collection and structure refinement statistics

\begin{tabular}{|c|c|}
\hline & $\mathbf{G A B A}_{\mathbf{A}} \mathbf{R}-\beta 3_{\text {cryst }}$ \\
\hline \multicolumn{2}{|l|}{ Data collection } \\
\hline Space group & $\mathrm{C} 2$ \\
\hline \multicolumn{2}{|l|}{ Cell dimensions } \\
\hline$a, b, c(\AA)$ & $174.1,108.9,207.4$ \\
\hline$a, \beta, \gamma\left({ }^{\circ}\right)$ & $90.0,107.4,90.0$ \\
\hline Wavelength $(\AA)$ & 0.976 \\
\hline Resolution ( $\mathrm{A})$ & $98.96-2.97(3.05-2.97)$ \\
\hline$R_{\text {merge }}$ & $0.077(0.833)$ \\
\hline$R_{\mathrm{pim}}$ & $0.034(0.362)$ \\
\hline$I / \sigma I$ & $13.5(2.0)$ \\
\hline Completeness (\%) & $99.8(99.8)$ \\
\hline Redundancy & $6.8(7.1)$ \\
\hline Wilson B factor $\left(\AA^{2}\right)$ & 74.07 \\
\hline \multicolumn{2}{|l|}{ Refinement } \\
\hline Resolution ( & $40.0-2.97(3.05-2.97)$ \\
\hline No. reflections & 76328 (5599) \\
\hline$R_{\text {work }}$ & $0.207(0.237)$ \\
\hline$R_{\text {free }}$ & $0.227(0.278)$ \\
\hline No. atoms & 13972 \\
\hline Protein & 13643 \\
\hline N-linked glycans & 279 \\
\hline
\end{tabular}




\begin{tabular}{ll}
\hline & $\mathbf{G A B A}_{\mathbf{A}} \mathbf{R}-\boldsymbol{\beta} \mathbf{3}_{\text {cryst }}$ \\
\hline Benzamidine & 45 \\
Chloride & 5 \\
B-factors $\left(\AA^{2}\right)$ & \\
Protein main/side chains & $97.2 / 105.4$ \\
N-linked glycans & 139.0 \\
Benzamidine & 129.9 \\
Chloride & 104.4 \\
R.m.s deviations & \\
Bond lengths $(\AA)$ & 0.010 \\
Bond angles $\left({ }^{\circ}\right)$ & 1.060 \\
\hline
\end{tabular}

- This structure was determined from one crystal.

- Numbers in parentheses refer to the highest resolution shell.

- $R_{\text {free }}$ was calculated as per $R_{\text {Work }}$ for a $5 \%$ subset of reflections that was not used in the crystallographic refinement.

- Ramachandran statistics and Molprobity scores are included in the Methods section.

\section{Supplementary Material}

Refer to Web version on PubMed Central for supplementary material.

\section{Acknowledgments}

We thank T. Malinauskas, Y. Kong and staff at Diamond Light Source beamlines I03 and I24 for assistance at the synchrotron; K. Harlos and T. Walter for technical support with crystallization; G. Schertler and J. Standfuss for advice concerning the Rho-1D4 affinity purification method; T. Nakagawa for electron microscopy sample examination; F. Ashcroft, S. Tucker, M. Clausen and P. Proks for access to electrophysiology equipment and assistance with electrophysiological recordings; M. Sansom, L. Carpenter, S. Newstead, I. de Moraes and members of the Aricescu laboratory for discussions; E.Y. Jones, D.I. Stuart and C. Siebold for reading the manuscript. This work was supported by grants from the Wellcome Trust (OXION: Ion channels and Disease Initiative, 084655), the UK Medical Research Council (G0700232) and the Royal Society (RG090810). Further support from the Wellcome Trust Core Award Grant Number 090532/Z/09/Z is acknowledged. P.S.M. was a Wellcome Trust OXION Training Fellow. A.R.A. is an MRC Senior Research Fellow.

\section{REFERENCES}

1. Rabow LE, Russek SJ, Farb DH. From ion currents to genomic analysis: recent advances in GABAA receptor research. Synapse. 1995; 21:189-274. [PubMed: 8578436]

2. Grenningloh G, et al. Glycine vs GABA receptors. Nature. 1987; 330:25-26. [PubMed: 2823147]

3. Simon J, Wakimoto H, Fujita N, Lalande M, Barnard EA. Analysis of the set of GABA(A) receptor genes in the human genome. J. Biol. Chem. 2004; 279:41422-41435. [PubMed: 15258161]

4. Sigel E, Steinmann ME. Structure, function, and modulation of GABA(A) receptors. J. Biol. Chem. 2012; 287:40224-40231. [PubMed: 23038269]

5. Yip GM, et al. A propofol binding site on mammalian GABAA receptors identified by photolabeling. Nat. Chem. Biol. 2013; 9:715-720. [PubMed: 24056400]

6. Karlin A, Akabas MH. Toward a structural basis for the function of nicotinic acetylcholine receptors and their cousins. Neuron. 1995; 15:1231-1244. [PubMed: 8845149]

7. Miller PS, Smart TG. Binding, activation and modulation of Cys-loop receptors. Trends Pharmacol. Sci. 2010; 31:161-174. [PubMed: 20096941]

8. Rudolph U, Knoflach F. Beyond classical benzodiazepines: novel therapeutic potential of GABAA receptor subtypes. Nat Rev Drug Discov. 2011; 10:685-697. doi:10.1038/nrd3502. [PubMed: 21799515] 
9. Li GD, et al. Identification of a GABAA receptor anesthetic binding site at subunit interfaces by photolabeling with an etomidate analog. J. Neurosci. 2006; 26:11599-11605. [PubMed: 17093081]

10. Wallner M, Hanchar HJ, Olsen RW. Ethanol enhances alpha 4 beta 3 delta and alpha 6 beta 3 delta gamma-aminobutyric acid type A receptors at low concentrations known to affect humans. Proc. Natl. Acad. Sci. U S A. 2003; 100:15218-15223. [PubMed: 14625373]

11. Belelli D, Lambert JJ. Neurosteroids: endogenous regulators of the GABA(A) receptor. Nat. Rev. Neurosci. 2005; 6:565-575. [PubMed: 15959466]

12. Brejc K, et al. Crystal structure of an ACh-binding protein reveals the ligand-binding domain of nicotinic receptors. Nature. 2001; 411:269-276. [PubMed: 11357122]

13. Miyazawa A, Fujiyoshi Y, Unwin N. Structure and gating mechanism of the acetylcholine receptor pore. Nature. 2003; 423:949-955. [PubMed: 12827192]

14. Unwin N. Refined structure of the nicotinic acetylcholine receptor at 4A resolution. J. Mol. Biol. 2005; 346:967-989. [PubMed: 15701510]

15. Hilf RJ, Dutzler R. X-ray structure of a prokaryotic pentameric ligand-gated ion channel. Nature. 2008; 452:375-379. [PubMed: 18322461]

16. Bocquet $\mathrm{N}$, et al. X-ray structure of a pentameric ligand-gated ion channel in an apparently open conformation. Nature. 2009; 457:111-114. [PubMed: 18987633]

17. Hibbs RE, Gouaux E. Principles of activation and permeation in an anion-selective Cys-loop receptor. Nature. 2011; 474:54-60. [PubMed: 21572436]

18. Nury H, et al. X-ray structures of general anaesthetics bound to a pentameric ligand-gated ion channel. Nature. 2011; 469:428-431. [PubMed: 21248852]

19. Jansen M, Bali M, Akabas MH. Modular design of Cys-loop ligand-gated ion channels: functional 5-HT3 and GABA rho1 receptors lacking the large cytoplasmic M3M4 loop. J. Gen. Physiol. 2008; 131:137-146. [PubMed: 18227272]

20. Hansen SB, Wang HL, Taylor P, Sine SM. An ion selectivity filter in the extracellular domain of Cys-loop receptors reveals determinants for ion conductance. J. Biol. Chem. 2008; 283:3606636070. [PubMed: 18940802]

21. Sauguet L, et al. Structural basis for ion permeation mechanism in pentameric ligand-gated ion channels. EMBO J. 2013; 32:728-741. [PubMed: 23403925]

22. Gurba KN, Hernandez CC, Hu N, Macdonald RL. GABRB3 mutation, G32R, associated with childhood absence epilepsy alters alpha1beta3gamma2L gamma-aminobutyric acid type A (GABAA) receptor expression and channel gating. J. Biol. Chem. 2012; 287:12083-12097. [PubMed: 22303015]

23. Sancar F, Czajkowski C. A GABAA receptor mutation linked to human epilepsy (gamma2R43Q) impairs cell surface expression of alphabetagamma receptors. J. Biol. Chem. 2004; 279:4703447039. [PubMed: 15342642]

24. Epi4K Consortium. et al. De novo mutations in epileptic encephalopathies. Nature. 2013; 501:217221. [PubMed: 23934111]

25. Bergmann R, Kongsbak K, Sorensen PL, Sander T, Balle T. A Unified Model of the GABA(A) Receptor Comprising Agonist and Benzodiazepine Binding Sites. Plos One. 2013; 8:e52323. [PubMed: 23308109]

26. Hansen SB, et al. Structures of Aplysia AChBP complexes with nicotinic agonists and antagonists reveal distinctive binding interfaces and conformations. EMBO J. 2005; 24:3635-3646. [PubMed: 16193063]

27. Huang $\mathrm{S}$, et al. Complex between alpha-bungarotoxin and an alpha7 nicotinic receptor ligandbinding domain chimaera. Biochem. J. 2013; 454:303-310. [PubMed: 23800261]

28. Celie $\mathrm{PH}$, et al. Nicotine and carbamylcholine binding to nicotinic acetylcholine receptors as studied in AChBP crystal structures. Neuron. 2004; 41:907-914. [PubMed: 15046723]

29. Newell JG, McDevitt RA, Czajkowski C. Mutation of glutamate 155 of the GABAA receptor beta2 subunit produces a spontaneously open channel: a trigger for channel activation. J. Neurosci. 2004; 24:11226-11235. [PubMed: 15601928]

30. Venkatachalan SP, Czajkowski C. A conserved salt bridge critical for GABA(A) receptor function and loop C dynamics. Proc. Natl. Acad. Sci. U S A. 2008; 105:13604-13609. [PubMed: 18757734] 
31. Wagner DA, Czajkowski C, Jones MV. An arginine involved in GABA binding and unbinding but not gating of the GABA(A) receptor. J. Neurosci. 2004; 24:2733-2741. [PubMed: 15028766]

32. Mukhtasimova N, Free C, Sine SM. Initial coupling of binding to gating mediated by conserved residues in the muscle nicotinic receptor. J. Gen. Physiol. 2005; 126:23-39. [PubMed: 15955875]

33. Rees DC, Congreve M, Murray CW, Carr R. Fragment-based lead discovery. Nat. Rev. Drug Discov. 2004; 3:660-672. [PubMed: 15286733]

34. Lo WY, et al. Glycosylation of \{beta 2 subunits regulates GABAA receptor biogenesis and channel gating. J. Biol. Chem. 2010; 285:31348-31361. [PubMed: 20639197]

35. Miller PS, Da Silva HM, Smart TG. Molecular basis for zinc potentiation at strychnine-sensitive glycine receptors. J. Biol. Chem. 2005; 280:37877-37884. [PubMed: 16144831]

36. Buhr A, et al. Functional characterization of the new human GABA(A) receptor mutation beta3(R192H). Hum. Genet. 2002; 111:154-160. [PubMed: 12189488]

37. Dellisanti CD, Yao Y, Stroud JC, Wang ZZ, Chen L. Crystal structure of the extracellular domain of nAChR alpha1 bound to alpha-bungarotoxin at 1.94 A resolution. Nat. Neurosci. 2007; 10:953962. [PubMed: 17643119]

38. Lee WY, Sine SM. Principal pathway coupling agonist binding to channel gating in nicotinic receptors. Nature. 2005; 438:243-247. [PubMed: 16281039]

39. Akabas MH. Using molecular dynamics to elucidate the structural basis for function in pLGICs. Proc. Natl. Acad. Sci. U S A. 2013; 110:16700-16701. [PubMed: 24096580]

40. Baulac S, et al. First genetic evidence of GABA(A) receptor dysfunction in epilepsy: a mutation in the gamma2-subunit gene. Nat. Genet. 2001; 28:46-48. [PubMed: 11326274]

41. Lape R, Plested AJ, Moroni M, Colquhoun D, Sivilotti LG. The alpha1K276E startle disease mutation reveals multiple intermediate states in the gating of glycine receptors. J. Neurosci. 2012; 32:1336-1352. [PubMed: 22279218]

42. Xu M, Akabas MH. Identification of channel-lining residues in the M2 membrane-spanning segment of the GABA(A) receptor alpha1 subunit. J. Gen. Physiol. 1996; 107:195-205. [PubMed: 8833341]

43. Cymes GD, Ni Y, Grosman C. Probing ion-channel pores one proton at a time. Nature. 2005; 438:975-980. [PubMed: 16355215]

44. Unwin N, Fujiyoshi Y. Gating movement of acetylcholine receptor caught by plunge-freezing. J. Mol. Biol. 2012; 422:617-634. [PubMed: 22841691]

45. Horenstein J, Akabas MH. Location of a high affinity Zn2+ binding site in the channel of alphalbeta1 gamma-aminobutyric acidA receptors. Mol. Pharmacol. 1998; 53:870-877. [PubMed: 9584213]

46. Rajendra S, et al. Mutation of an arginine residue in the human glycine receptor transforms betaalanine and taurine from agonists into competitive antagonists. Neuron. 1995; 14:169-175. [PubMed: 7826634]

47. Young GT, Zwart R, Walker AS, Sher E, Millar NS. Potentiation of alpha7 nicotinic acetylcholine receptors via an allosteric transmembrane site. Proc. Natl. Acad. Sci. U S A. 2008; 105:1468614691. [PubMed: 18791069]

48. daCosta CJ, Free CR, Corradi J, Bouzat C, Sine SM. Single-channel and structural foundations of neuronal alpha7 acetylcholine receptor potentiation. J. Neurosci. 2011; 31:13870-13879. [PubMed: 21957249]

49. Shan Q, Haddrill JL, Lynch JW. Ivermectin, an unconventional agonist of the glycine receptor chloride channel. J. Biol. Chem. 2001; 276:12556-12564. [PubMed: 11278873]

50. Jensen ML, et al. The beta subunit determines the ion selectivity of the GABAA receptor. J. Biol. Chem. 2002; 277:41438-41447. [PubMed: 12177063]

51. Aricescu AR, Lu W, Jones EY. A time- and cost-efficient system for high-level protein production in mammalian cells. Acta. Crystallogr. D. Biol. Crystallogr. 2006; 62:1243-1250. [PubMed: 17001101]

52. Zacharias DA, Violin JD, Newton AC, Tsien RY. Partitioning of lipid-modified monomeric GFPs into membrane microdomains of live cells. Science. 2002; 296:913-916. [PubMed: 11988576] 
53. Nagai T, et al. A variant of yellow fluorescent protein with fast and efficient maturation for cellbiological applications. Nat. Biotechnol. 2002; 20:87-90. [PubMed: 11753368]

54. Molday RS, MacKenzie D. Monoclonal antibodies to rhodopsin: characterization, cross-reactivity, and application as structural probes. Biochemistry. 1983; 22:653-660. [PubMed: 6188482]

55. Oprian DD, Molday RS, Kaufman RJ, Khorana HG. Expression of a synthetic bovine rhodopsin gene in monkey kidney cells. Proc. Natl. Acad. Sci. U S A. 1987; 84:8874-8878. [PubMed: 2962193]

56. Kawate T, Gouaux E. Fluorescence-detection size-exclusion chromatography for precrystallization screening of integral membrane proteins. Structure. 2006; 14:673-681. [PubMed: 16615909]

57. Reeves PJ, Callewaert N, Contreras R, Khorana HG. Structure and function in rhodopsin: highlevel expression of rhodopsin with restricted and homogeneous $\mathrm{N}$-glycosylation by a tetracyclineinducible N-acetylglucosaminyltransferase I-negative HEK293S stable mammalian cell line. Proc. Natl. Acad. Sci. U S A. 2002; 99:13419-13424. [PubMed: 12370423]

58. Aricescu AR, Owens RJ. Expression of recombinant glycoproteins in mammalian cells: towards an integrative approach to structural biology. Curr. Opin. Struct. Biol. 2013; 23:345-356. [PubMed: 23623336]

59. Tasneem A, Iyer LM, Jakobsson E, Aravind L. Identification of the prokaryotic ligand-gated ion channels and their implications for the mechanisms and origins of animal Cys-loop ion channels. Genome Biol. 2005; 6:R4. [PubMed: 15642096]

60. Jansen M, Bali M, Akabas MH. Modular design of Cys-loop ligand-gated ion channels: functional 5-HT3 and GABA rho1 receptors lacking the large cytoplasmic M3M4 loop. J. Gen. Physiol. 2008; 131:137-146. [PubMed: 18227272]

61. Chaudhary S, Pak JE, Gruswitz F, Sharma V, Stroud RM. Overexpressing human membrane proteins in stably transfected and clonal human embryonic kidney 293S cells. Nat. Protoc. 2012; 7:453-466. [PubMed: 22322218]

62. Chang VT, et al. Glycoprotein structural genomics: solving the glycosylation problem. Structure. 2007; 15:267-273. [PubMed: 17355862]

63. Walter TS, et al. A procedure for setting up high-throughput nanolitre crystallization experiments. Crystallization workflow for initial screening, automated storage, imaging and optimization. Acta. Crystallogr. D. Biol. Crystallogr. 2005; 61:651-657. [PubMed: 15930615]

64. Parker JL, Newstead S. Current trends in alpha-helical membrane protein crystallization: an update. Protein Sci. 2012; 21:1358-1365. [PubMed: 22811290]

65. Winter G. xia2: an expert system for macromolecular crystallography data reduction. Journal of Applied Crystallography. 2009; 43:186-190.

66. Hibbs RE, Gouaux E. Principles of activation and permeation in an anion-selective Cys-loop receptor. Nature. 2011; 474:54-60. [PubMed: 21572436]

67. McCoy AJ, et al. Phaser crystallographic software. Journal of Applied Crystallography. 2007; 40:658-674. [PubMed: 19461840]

68. Terwilliger TC, et al. Iterative model building, structure refinement and density modification with the PHENIX AutoBuild wizard. Acta. Crystallogr. D. Biol. Crystallogr. 2008; 64:61-69. [PubMed: 18094468]

69. Emsley P, Lohkamp B, Scott WG, Cowtan K. Features and development of Coot. Acta. Crystallogr. D. Biol. Crystallogr. 2010; 66:486-501. [PubMed: 20383002]

70. Bricogne, G., et al. BUSTER. version 2.11.2. Global Phasing Ltd; Cambridge, United Kingdom: 2011.

71. Smart OS, et al. Exploiting structure similarity in refinement: automated NCS and target-structure restraints in BUSTER. Acta. Crystallogr. D. Biol. Crystallogr. 2012; 68:368-380. [PubMed: 22505257]

72. Chen VB, et al. MolProbity: all-atom structure validation for macromolecular crystallography. Acta. Crystallogr. D. Biol. Crystallogr. 2010; 66:12-21. [PubMed: 20057044]

73. Larkin MA, et al. Clustal W and Clustal X version 2.0. Bioinformatics. 2007; 23:2947-2948. [PubMed: 17846036]

74. Stuart DI, Levine M, Muirhead H, Stammers DK. Crystal structure of cat muscle pyruvate kinase at a resolution of 2.6 A. J. Mol. Biol. 1979; 134:109-142. [PubMed: 537059] 
75. Krissinel E, Henrick K. Inference of macromolecular assemblies from crystalline state. J. Mol. Biol. 2007; 372:774-797. [PubMed: 17681537]

76. Deprez C, et al. Solution structure of the E.coli TolA C-terminal domain reveals conformational changes upon binding to the phage g3p N-terminal domain. J. Mol. Biol. 2005; 346:1047-1057. [PubMed: 15701516]

77. Baker NA, Sept D, Joseph S, Holst MJ, McCammon JA. Electrostatics of nanosystems: application to microtubules and the ribosome. Proc. Natl. Acad. Sci. U S A. 2001; 98:10037-10041. [PubMed: 11517324]

78. Chovancova E, et al. CAVER 3.0: a tool for the analysis of transport pathways in dynamic protein structures. PLoS Comput. Biol. 2012; 8:e1002708. [PubMed: 23093919]

79. Hattori M, Hibbs RE, Gouaux E. A fluorescence-detection size-exclusion chromatography-based thermostability assay for membrane protein precrystallization screening. Structure. 2012; 20:1293-1299. [PubMed: 22884106]

80. Farre C, et al. Port-a-patch and patchliner: high fidelity electrophysiology for secondary screening and safety pharmacology. Comb. Chem. High Throughput Screen. 2009; 12:24-37. [PubMed: 19149489]

81. Saras A, et al. Histamine action on vertebrate GABAA receptors: direct channel gating and potentiation of GABA responses. J. Biol. Chem. 2008; 283:10470-10475. [PubMed: 18281286]

82. Butts CA, et al. Identification of a fluorescent general anesthetic, 1-aminoanthracene. Proc Natl Acad Sci U S A. 2009; 106:6501-6506. [PubMed: 19346473] 

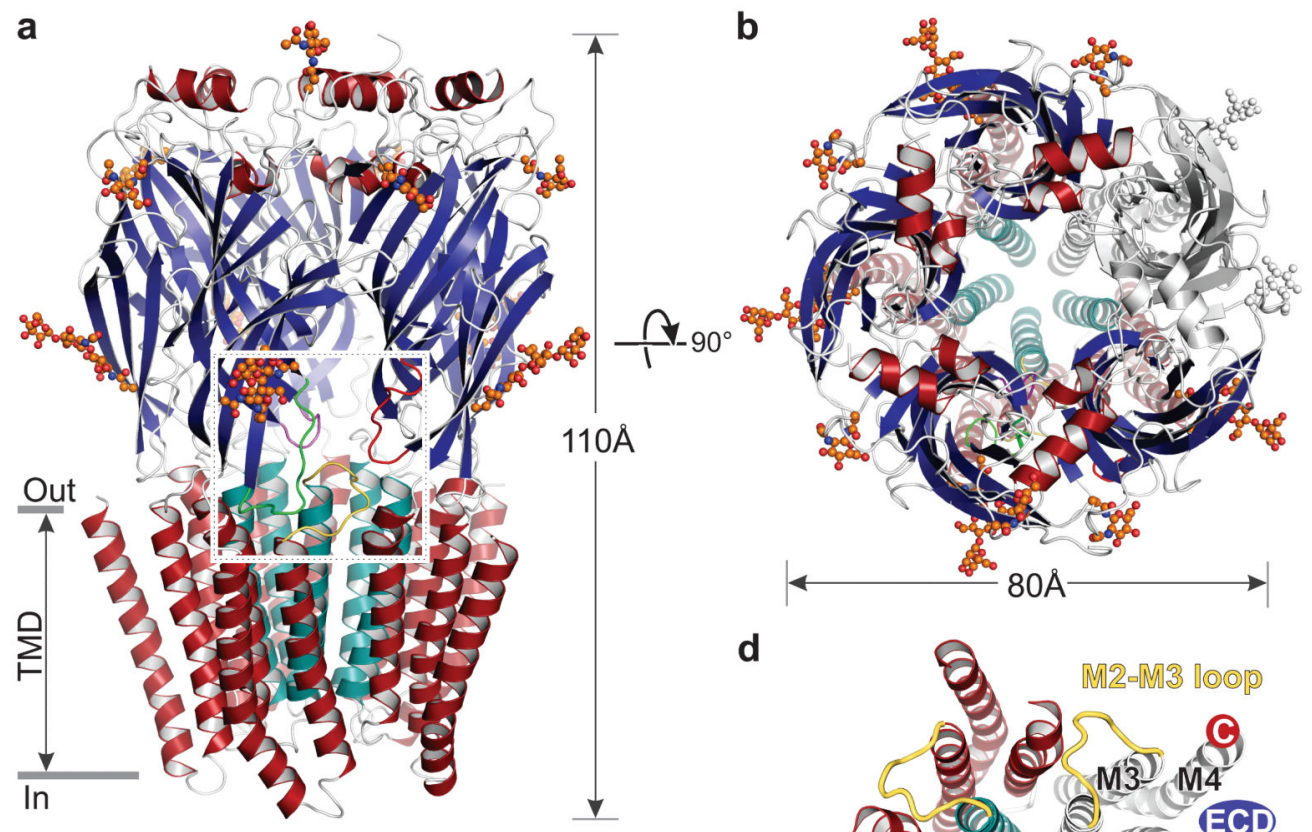

d
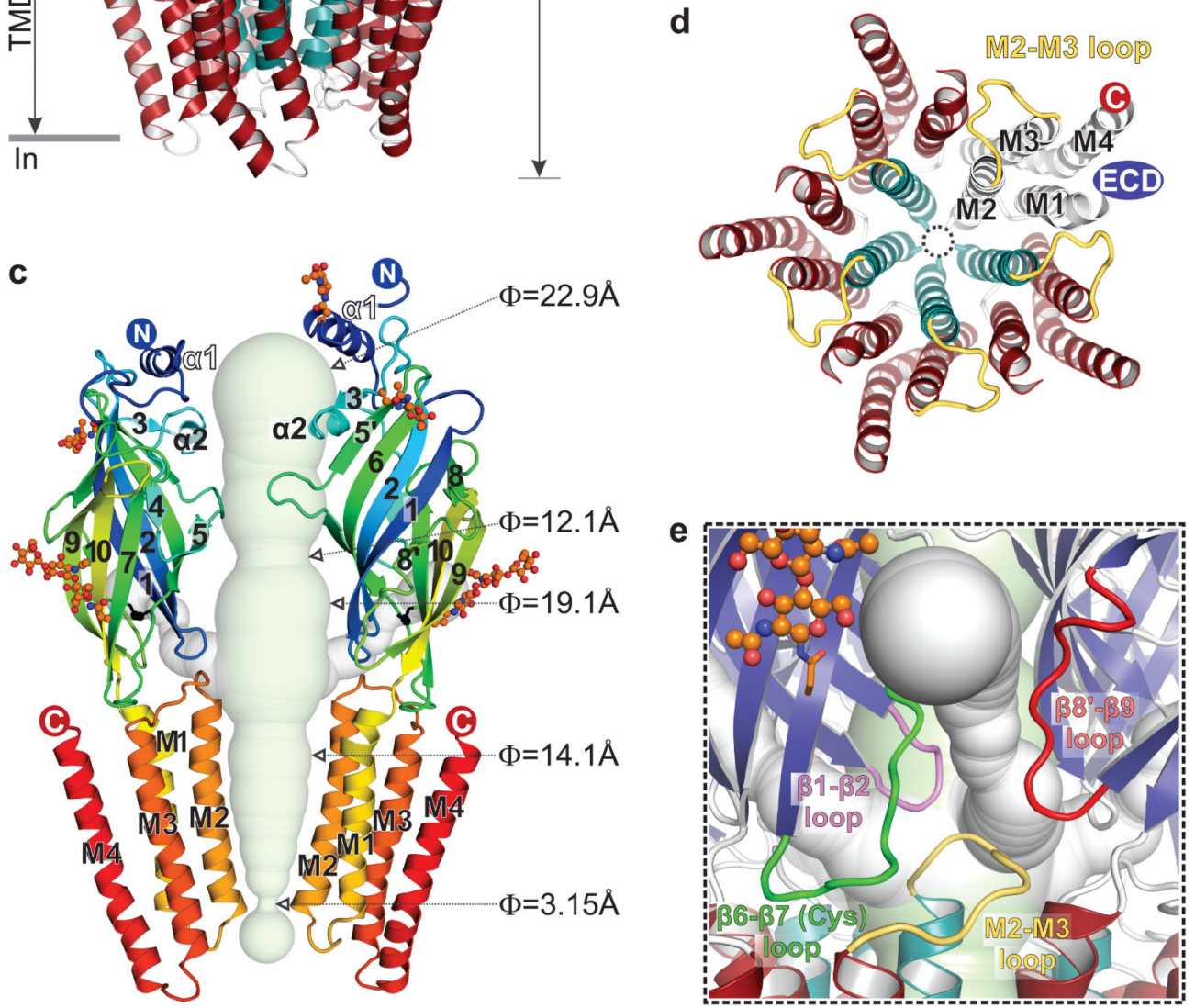

Figure 1. Architecture of $\mathbf{G A B A}_{\mathrm{A}} \mathbf{R}-\beta 3_{\text {cryst }}$

a, $\mathrm{GABA}_{\mathrm{A}} \mathrm{R}-\beta 3_{\text {cryst }}$ viewed parallel to the plasma membrane ( $\alpha$-helices red, except the porelining M2 shown in teal; $\beta$-strands blue; loops grey). N-linked glycans shown in orange "ball-and-stick" representation. b, View from the extracellular space (synaptic cleft) down the five-fold pseudo-symmetry axis, with a single subunit coloured in grey. c, Two subunits, rainbow coloured from blue $\mathrm{N}$-terminus to red $\mathrm{C}$-terminus, illustrating secondary structure nomenclature. A water-filled ECD vestibule and TMD pore shown in light green (diameter indicated periodically) runs through the five-fold pseudosymmetry axis of the pentamer, 
joined by lateral tunnels coming from between each of the subunit ECDs (two only shown for clarity, in grey). d, The pentameric transmembrane region, to illustrate the arrangement of helices M1-M4 and the M2-M3 loop (yellow). e, View of a lateral tunnel running between subunits into the central vestibule. 


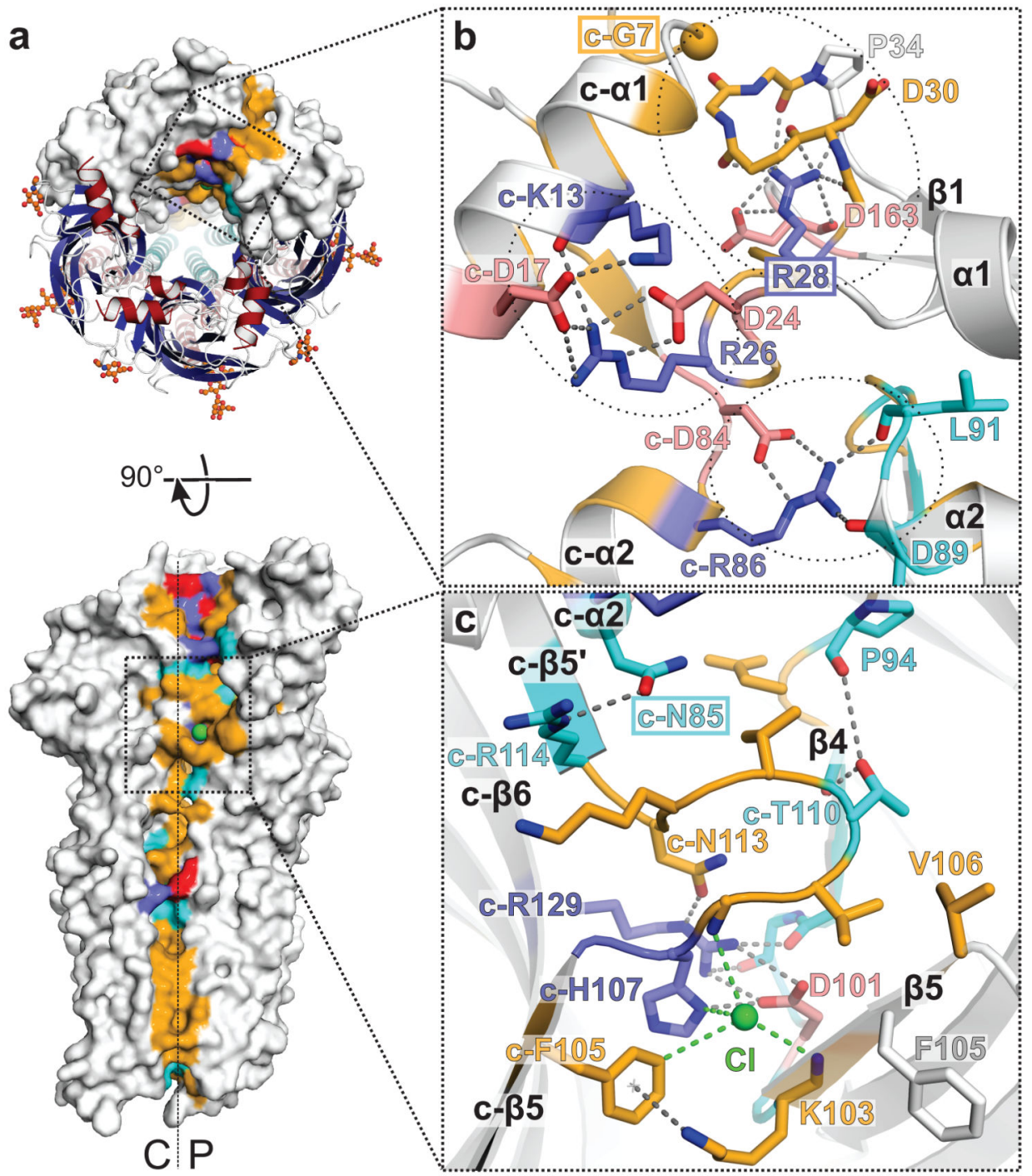

Figure 2. Assembly interactions in $\mathbf{G A B A}_{\mathbf{A}} \mathbf{R}-\beta 3_{\text {cryst }}$

a, Top-down view of the $\mathrm{GABA}_{\mathrm{A}} \mathrm{R}-\beta 3_{\text {cryst }}$ pentamer and side-on view from the vestibule of two neighbouring subunits, highlighting the nature of inter-subunit contacts between the "principal" face of one subunit and "complementary" face (residues marked by "c-") of the next. Salt-bridging residues are coloured purple and red, those forming putative hydrogenbonds in cyan, and residues forming van der Waals contacts in orange. b, The upper ECD close-up shows the inter-subunit a1- $\beta 1$ loop (upper dotted oval), the inter-subunit saltbridges connecting a1 helices (middle dotted oval) and inter-subunit a2-a2 interactions (lower dotted oval). Boxed residue labels correspond to disease mutations discussed in main text. c, The ECD anion-binding site and surrounding inter-subunit interface (chloride shown as a green sphere). Grey dashed lines indicate putative salt-bridges and hydrogen-bonds, green dashes indicate chloride coordination. 

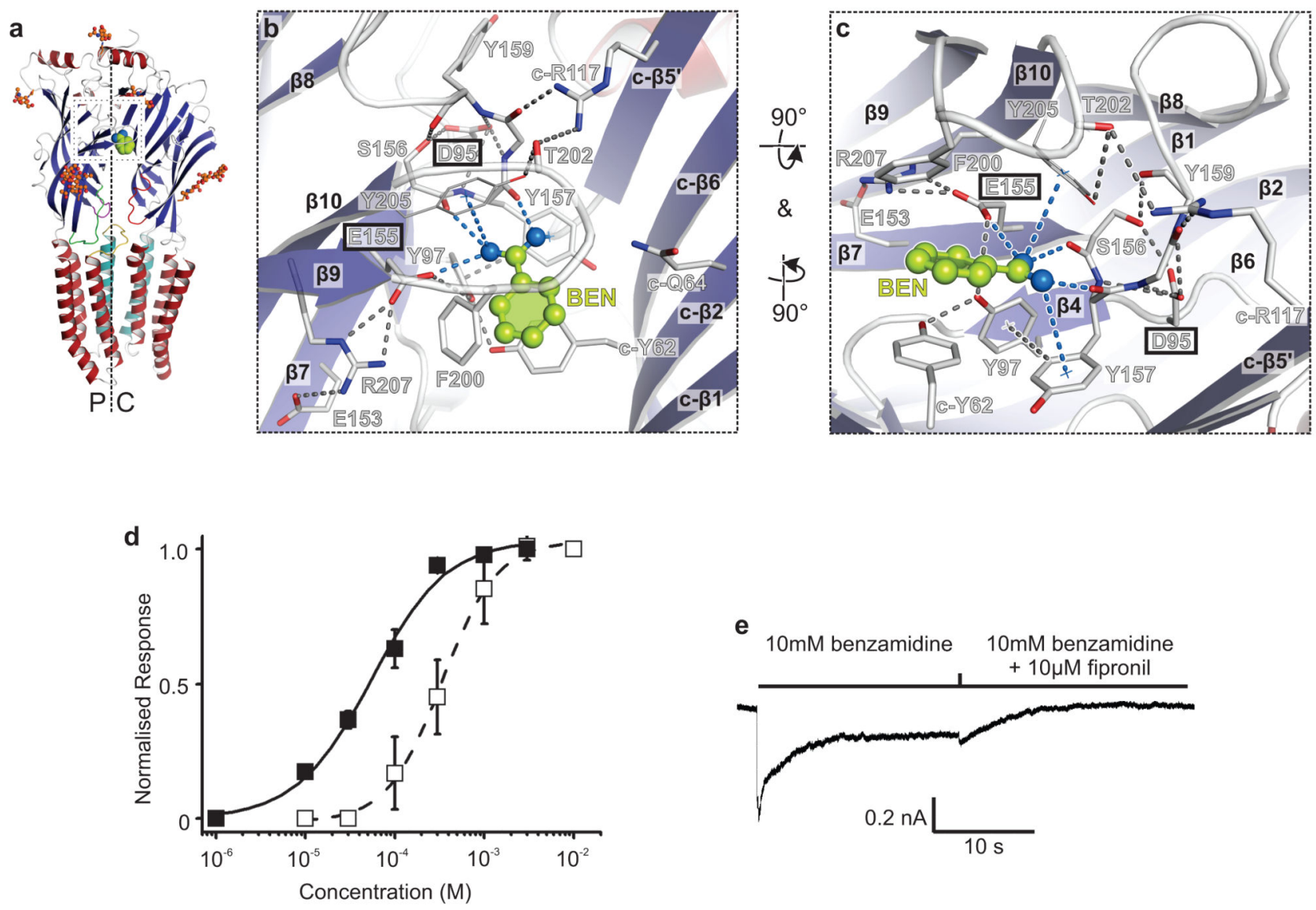

Figure 3. Neurotransmitter pocket occupied by the agonist benzamidine

a, Benzamidine (green/blue spheres) bound in the neurotransmitter pocket. Of note, the $\beta 8$ $\beta 8^{\prime}$ loop, known as loop F (Arg169-Ala174; running into the red loop) in heteromeric $\mathrm{GABA}_{\mathrm{A}}$ Rs does not contribute to the $\mathrm{GABA}_{\mathrm{A}} \mathrm{R} \beta 3_{\text {cryst }}$ orthosteric site. b, c, Benzamidine binding mode. "Complementary" face residues marked by "c-". Grey dashed lines indicate putative hydrogen-bonds, salt-bridges and cation- $\pi$ interactions; blue dashed lines indicate the coordination sphere of benzamidine nitrogen atoms. Boxed residue labels indicate disease mutations. d, Benzamidine dose-response curves determined by patch-clamp of $\mathrm{GABA}_{\mathrm{A}} \mathrm{R}-\beta 3_{\text {cryst }}$ expressed in $\mathrm{HEKS}-\mathrm{GnTI}^{-}$cells (solid line) and by thermostabilisation of $\mathrm{GABA}_{\mathrm{A}} \mathrm{R}-\beta 3_{\text {cryst }}$ in detergent micelles (dashed line; error bars are s.e.m.). e, Electrophysiological response to $10 \mathrm{mM}$ benzamidine and block by $10 \mu \mathrm{M}$ channel blocker fipronil (an alternative blocker, picrotoxin, also blocked $\mathrm{GABA}_{\mathrm{A}} \mathrm{R}-\beta 3_{\text {cryst }}$ currents Extended Data Figure 1d). 


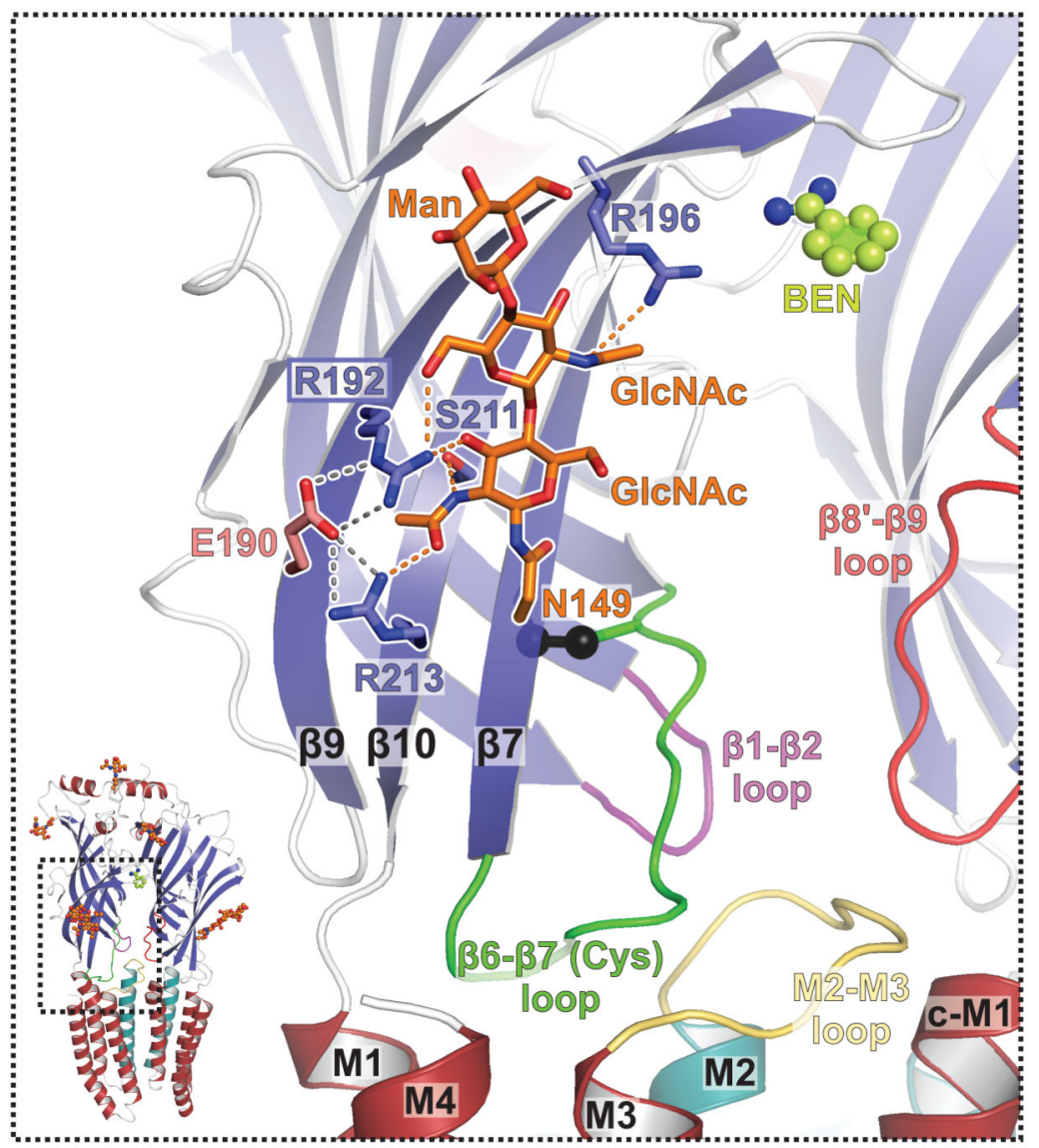

Figure 4. A conserved glycosylation site interacts with $\beta 9-\beta 10$ loop residues

Close-up of the N-linked glycosylation site 3 , attached to the $\beta 7$-strand that supports the $\beta 6$ $\beta 7$ (Cys) loop (Cys-bridge shown in black spheres) and its interactions with surrounding residues from the $\beta 9-\beta 10$ agonist binding loop (indicated by dashed orange lines; grey dashed lines highlight putative salt-bridges). Boxed residue labels correspond to disease mutations discussed in main text. 

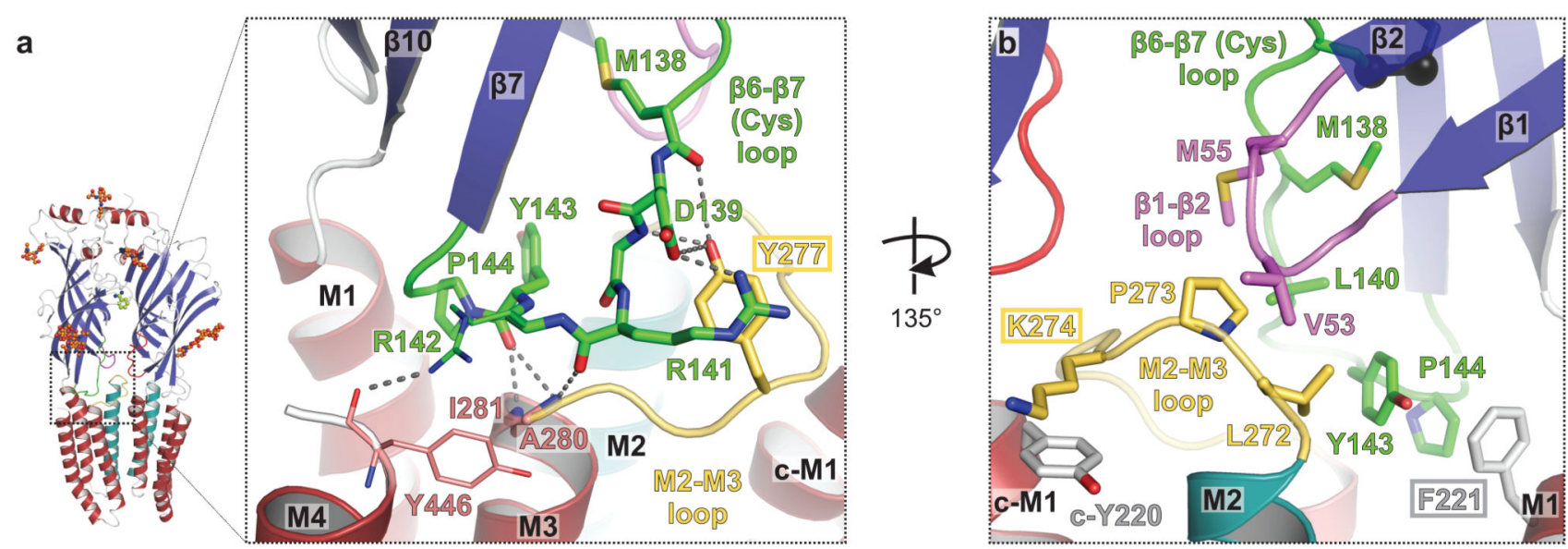

Figure 5. Structural coupling at the ECD-TMD interface

a, Side-on view of the ECD-TMD interface, rotated $135^{\circ}$ in $\mathbf{b} . \mathbf{a}$, Putative hydrogen bonds (indicated by grey dashed lines) between residues of the $\beta 6-\beta 7$ (Cys) loop, the outer portion of the M2-M2 loop and the top of M3 and M4 helices. b, Hydrophobic packing in the ECDTMD interface on the pore side, involving residues from the $\beta 6-\beta 7$ loop, the $\beta 1-\beta 2$ loop, the inner portion of the M2-M3 loop and the N-terminus of the M1 helix from a neighbouring subunit. Boxed residue labels correspond to disease mutations discussed in main text. 
a

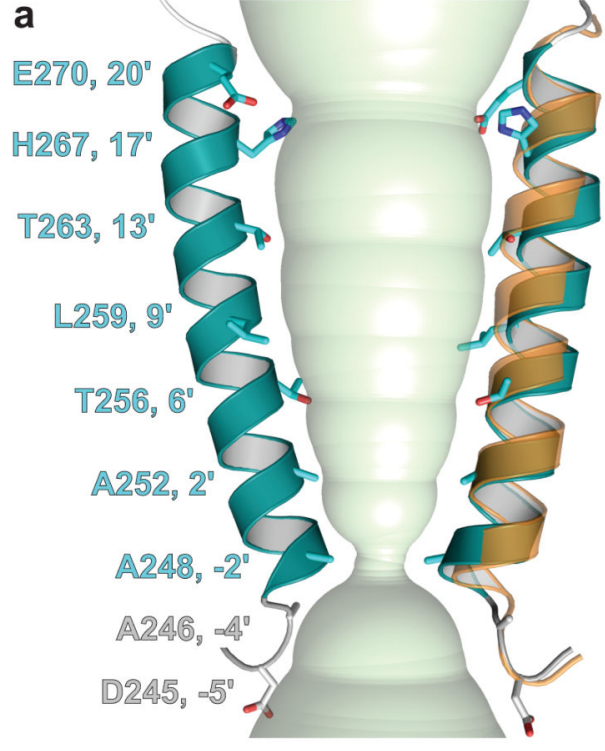

b

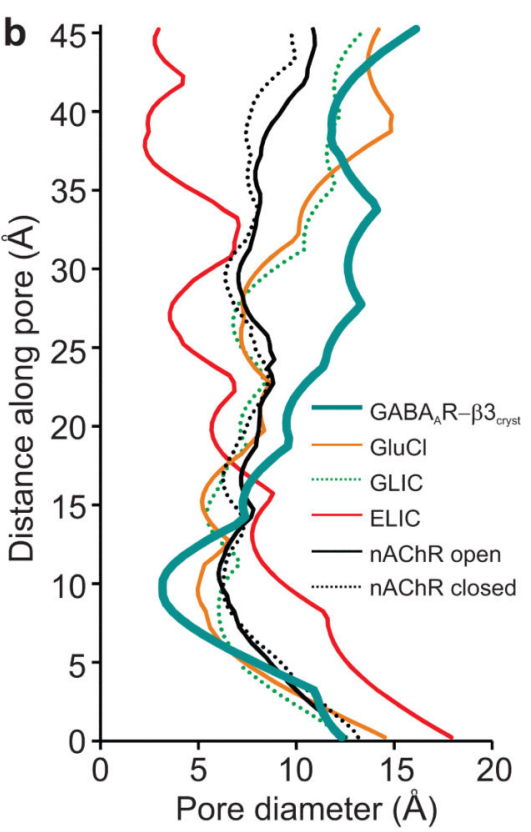

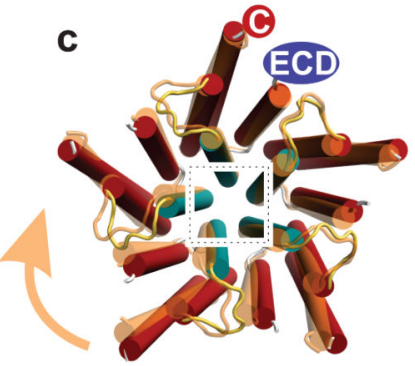

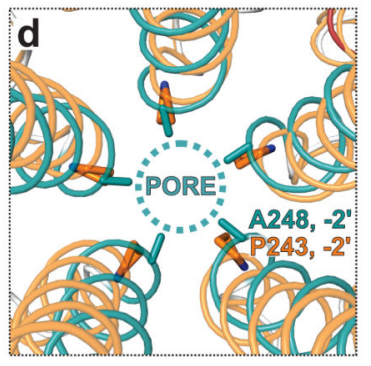

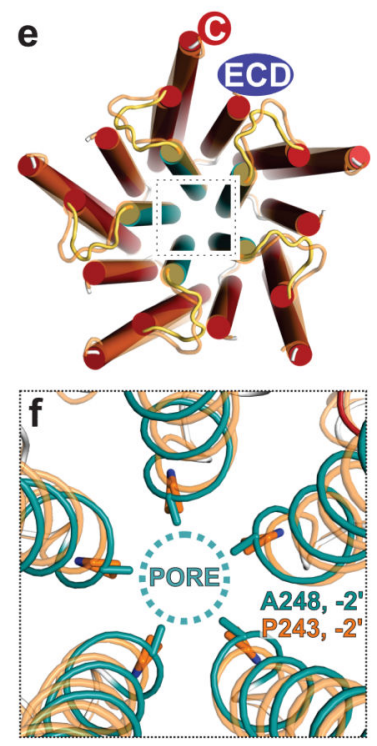

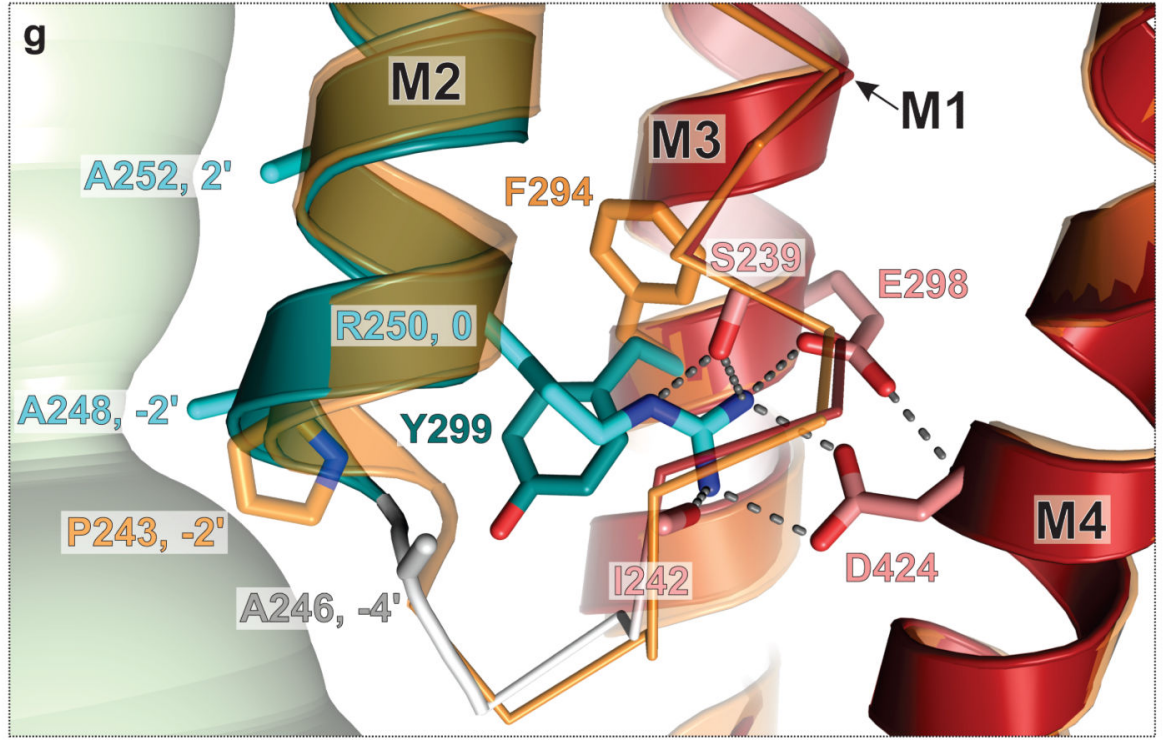

Figure 6. Structure of the ion channel in a desensitised state

a, Two GABA $A$ R- $\beta 3_{\text {cryst }} \mathrm{M} 2$ helices (teal), with side chains of pore-lining residues in stick representation. An equivalent GluCla (3RIF) M2 helix, in orange, illustrates its distinct flexure. b, Pore diameter of $\mathrm{GABA}_{\mathrm{A}} \mathrm{R}-\beta 3_{\text {cryst }}$ (teal) and related structures: open GluCla, open nAChR (4AQ9), closed nAChR (2BG9), open GLIC (4HFI) and closed ELIC (2VL0).

c, Chain A superposition of pentameric $\mathrm{GABA}_{\mathrm{A}} \mathrm{R}-\beta 3_{\text {cryst }}$ (red/teal) over GluCla (orange), revealing the relative rotation of transmembrane regions. $\mathbf{d}$, The pore constriction at $-2^{\prime}$ A248 in $\mathrm{GABA}_{\mathrm{A}} \mathrm{R}-\beta 3_{\text {cryst }}$ compared to GluCla at $-2^{\prime} \mathrm{P} 243$, using alignment in c. e, Superposition of individual $\mathrm{GABA}_{A}-\beta 3_{\text {cryst }}$ subunit TMDs over GluCla removes the relative rotation, but the pore remains shut, f. g, GABA ${ }_{A} R-\beta 3_{\text {cryst }}$ (red/teal) showing Tyr 299 
"pressing" M2 to constrict the channel. In GluCla (orange) Phe294 points upwards, enabling an open pore conformation. 